\title{
El detalle como intensificación de la forma en el Library and Administration Building, del Illinois Institute of Technology, de Ludwig Mies van der Rohe
}

\author{
M. Augusta Hermida P. \\ Departamento de Proyectos Arquitectónicos, Universidad Politécnica de Catalunya, Barcelona, España \\ Autor de correspondencia: augusta.hermida@ucuenca.edu.ec
}

Fecha de recepción: 4 de octubre 2012 - Fecha de aceptación: 20 de enero 2013

\section{RESUMEN}

La pregunta central que se trata de responder en este artículo es en qué medida los detalles constructivos influyen en la construcción de la forma y, por ende, en la calidad de los proyectos arquitectónicos. Se eligió a Mies van der Rohe, uno de los más claros exponentes de la Arquitectura Moderna, por la precisión e intensidad de las que supo dotar a sus obras, en donde, el detalle es una condición del proyecto, de modo que más que un corolario técnico, se trata de un momento de intensificación de la forma. La razón que motivó la elección del Library and Administration Building, es que el carácter esencial del detalle se acentúa al abordar los pormenores de un proyecto no construido, en este alcanza toda su dimensión de condición fundamental de la forma: o se define el detalle o no existe el proyecto. Se entiende el detalle como momento básico del proyecto, presente en el momento mismo de la concepción. El detalle, en la medida que condensa el sistema constructivo entero, es un requisito fundamental de la forma: el momento intenso de relación -constructiva y visualde los materiales.

Se partió de la revisión de los dibujos originales de Mies van der Rohe y de la selección de los detalles más representativos; y, se utilizó los recursos de la tecnología digital para el modelado geométrico básico y la simulación visual. A través de este proceso se dotó de materialidad a los diversos elementos y se visualizaron sus relaciones desde diversos puntos de vista, se entendió a la construcción virtual como alternativa a la construcción real cuando ésta no es viable. Gracias a las ventajas de la tecnología, el edificio y los detalles pudieron ser construidos una y otra vez, permitiéndonos entender, de manera casi experimental, las razones que motivaron a Mies a desechar ciertas propuestas e inclinarse por otras.

El trabajo reveló que Mies van der Rohe siempre buscó la solución más universal, económica y abstracta, y se comprobó que la correcta relación entre materiales se convirtió en el aspecto intensificador de su obra.

Palabras clave: Arquitectura, detalle, forma, construcción visual, Ludwig Mies van der Rohe.

\begin{abstract}
The key question addressed in this paper is to what extent constructive details influence the constructional form and ultimately the quality of architectural projects. To this end Mies van der Rohe, one of the most significant exponents of Modern Architecture, was selected because of the precision and intensity with which he designed his work. In particular he paid enormously attention to the detail, which for Mies meant more than a mere technical corollary, but a way to accentuate the form. The non-built Library and Administration Building was elected as study case because of the large variety of the constructional details in all their dimensions and form elaborated in the multitude of drawings designed in preparation of the architectural project. According to Mies van der Rohe a project concretizes by the design of the constructional details. He considers the details as basic components in the concretization of the conception. Details condenses the entire constructive system, a fundamental
\end{abstract}


requirement of the form, and forming an intense moment of -constructive and visual- relation between materials.

The analysis was based on reviewing Mies van der Rohe's original drawings and with the selection of the most representative details. Using the digital technology the basic geometry of constructive details were modeled and visualized. The approach enabled the materialization of the diverse elements and the visualization of the relations between elements from different points of view. The exercise revealed that virtual construction is a valuable alternative to real construction when the latter for one or other reason is not possible. With the technology we reconstructed again and again the building and the details which enabled us to better understand in an experimental way the reasons why Mies discarded certain proposals and leaned towards others.

Our study unfolded that Mies van der Rohe always looked for the most universal, economic and abstract solution, and it was proven that the correct relation between materials leads to the intensification of architectural projects.

Keywords: Architecture, detail, form, visual construction, Ludwig Mies van der Rohe.

\section{INTRODUCCIÓN}

Sabemos que el término "forma" tiene dos sentidos según provenga del término griego "eidos" o del alemán "gestalt". En el primer caso, la forma se identifica con la esencial constitución interna de un objeto, y alude a la disposición y ordenación general de sus partes, de manera que la forma se identifica con el concepto de estructura; en el segundo caso, la forma se refiere a la apariencia del objeto: a su aspecto, de modo que se convierte en sinónimo de figura. La noción de forma como estructura remite a las dimensiones inteligibles del objeto y abre la puerta a la concepción abstracta. La noción de forma como figura se refiere a las dimensiones sensibles o perceptibles del objeto y constituye la base de la elaboración figurativa (Martí, 2005). La forma entendida como estructura y como manifestación de orden es la definición que se usará para el presente artículo.

El proyecto arquitectónico consistente parte de la identificación de los criterios de orden que le subyacen. Conceptos como la simetría, las relaciones geométricas, las proporciones matemáticas, rigen muchas de las composiciones artísticas del ser humano y le confieren su belleza a lo largo de la historia. A partir del siglo XX se busca la belleza a través de nuevos equilibrios y a través de encontrar los aspectos más universales del fenómeno: su esencia. En este sentido existe una estrecha relación entre la belleza y las matemáticas.

Los elementos de la naturaleza no tienen forma, solo tienen una estructura orgánica que vincula sus elementos por lo que la condición de arte, es decir la presencia de forma, sólo se alcanza cuando el pintor o fotógrafo logran manifestar una estructura que no es accesible a la mirada común. En la música el pentagrama es como una gran fórmula matemática en la que el músico coloca los factores que son las notas y que reparte en compases, ritmos, melodías y escalas. La música es construcción de forma por excelencia y aunque entre las distintas culturas del mundo existe una gran diversidad de tipos de escalas, lo cierto es que también hay una serie de similitudes que nos permiten pensar que en músicas muy alejadas geográfica e históricamente subyacen unos principios universales basados en conceptos matemáticos. Nuestro oído se ha ido desarrollando con los siglos, es sensible a una serie de proporciones o de elementos matemáticos y ha sabido responder a estos sin ninguna necesidad de ser conscientes de que existían estas relaciones (Punset, 2008). En la arquitectura debemos buscar aquellas relaciones que hacen que el fenómeno sea bello: aquellas soluciones de programa y de detalle que sean universales y abstractas. Ese en definitiva es el fin último de este trabajo.

Al tomar como centro al Library and Administration Building se puede entender el proceso de diseño del campus no como una arquitectura hecha de objetos sino de relaciones entre ellos; además se observa cómo la manera de concebir los detalles es la misma que la de los edificios en su totalidad: sistemática y económica; y que, su definición se hace básicamente con la mirada. Como dijo este arquitecto, a través de Neumeyer (1995) "Debemos distinguir el núcleo de la verdad. Sólo las 
preguntas que se refieren a la esencia de las cosas tienen sentido. Las respuestas que encuentra una generación a esta pregunta, son su aportación a la arquitectura."

\section{EL DETALLE EN EL LIBRARY AND ADMINISTRATION BUILDING DEL ILLINOIS INSTITUTE OF TECHNOLOGY (IIT)}

Mies nace el 27 de marzo de 1886 en Aquisgrán (Aachen), Alemania, por lo que en 1937, cuando llega a Estados Unidos, tiene más de 50 años. Para entonces Mies ya es conocido en el ámbito arquitectónico de América pues en 1932, en el catálogo de la exposición de "Arquitectura Internacional", en el Museo de Arte Moderno de Nueva York, aparece conjuntamente con Frank Lloyd Wright, Le Corbusier y Gropius. En 1938, Mies es nombrado Director de la School of Architecture en el Armour Institute de Chicago, y abre su despacho para desarrollar el encargo del planeamiento y diseño del nuevo campus de esta institución. El éxito de Mies van der Rohe en América se debe a un aprendizaje recíproco. Es consciente de que el arte de la construcción tiene sus orígenes en los materiales, y al igual que en Alemania conoce el ladrillo y el vidrio, en América encuentra el acero, en una escala y en una cantidad que antes sólo había podido soñar (Schulze, 1989). Para Mies el edificio de acero y cristal es necesariamente la forma apropiada de la construcción para la ciudad moderna. En cuanto Mies empieza con el proyecto tiene muy claro el papel de la estructura: las columnas y las vigas deben estar colocadas a intervalos regulares. Esta estructura debe rellenarse con materiales que se tengan a mano: el ladrillo y el vidrio resultan los más económicos.

Mies elige un módulo, que actúa como organizador y principio guía, y que sirve para determinar la posición de cada edificio del campus: una estructura clara da una solución arquitectónica que perdura (Carter, 1974). Se elige un módulo con la proporción del cuadrado doble, uno de los más viejos y efectivos sistemas de proporción en arquitectura: 24 x 24 pies (7,3 x 7,3 metros) y una altura de 12 pies (3,65 metros). Estas dimensiones resultan ser las más funcionales para las actividades que se desarrollan en el campus, y son fruto de un arduo trabajo de investigación que empieza en 1939.

Mies proyecta 35 edificios de los cuales 21 se construyen: 6 edificios con estructura de acero, 6 con acero revestido de hormigón, 6 con hormigón armado y 3 con muro portante. Entre los que nunca se llegan a construir está el Library and Administration Building. La escasez de acero en la época y un nivel bajo de prioridad debido a la II Guerra Mundial influye en el hecho de que no se construya. El proyecto del Library and Administration Building empieza en marzo de 1944 y Mies trabaja en él hasta 1945. El profundo trabajo de detalle de las partes componentes y, particularmente, de la articulación de la carpintería en diferentes condiciones fue decisivo para el desarrollo de las soluciones constructivas de todos los edificios del campus (The Museum of Modern Art, 1986). Al ser un edificio de una sola planta no requiere proteger la estructura contra incendios ventaja que le permite dejar expuestos todos los elementos estructurales, dentro y fuera, con la máxima claridad.

Previamente al diseño de este proyecto, Mies construye su primer proyecto en América, el Minerals and Metals Research Building que empieza en 1942 y finaliza en 1943. Es la primera vez que Mies experimenta con la relación entre la estructura de acero, los cerramientos de ladrillo y los planos de vidrio. Una vez terminado, Mies y sus colaboradores aprovechan la falta de presión para construir, desde febrero de 1943 hasta 1945, para desarrollar una serie de estudios detallados para los futuros edificios. Algunas de estas soluciones se vuelven elementos estándar en los siguientes edificios del IIT, que sólo varían en planta, altura y requerimientos espaciales. Entre estos el Metallurgy and Chemical Engineering Building, más conocido como Perlstein Hall; el Navy Building o Alumni Memorial Hall, que es el primero en construirse, y el Chemistry Building o Wishnick Hall, los tres entre 1945-1946. Estos volúmenes, de diferentes alturas y desplazados entre sí, forman, hoy por hoy, el único espacio en donde se puede percibir la propuesta espacial de Mies para los exteriores del IIT: el Callejón de Mies o Mies Alley (The Museum of Modern Art, 1986). El Library and Administration Building se convierte en el terreno sobre el cual Mies explora el concepto de espacio abierto universal que desarrolla posteriormente en el Crown Hall, entre 1950 y 1956. Debido al hecho de que el Library and Administration Building nunca se culmina, el Crown Hall se convierte en el edificio más 
significativo del campus y tiene la función de albergar el Departamento de Arquitectura, Diseño y Planeamiento.

El crecimiento del número de encargos durante los años cincuenta, junto con su dispersión geográfica y la rápida difusión de su fama en general, le apartan de sus deberes académicos en el campus. Entre 1949 y la inauguración del Edificio Seagram (altura 160m, 38 plantas, ciudad de Nueva York) en 1958, el estudio de Mies se ocupa de más de cien encargos independientes en tres continentes. La administración del IIT se irrita ante lo que entiende como una falta de atención de Mies hacia la terminación de ese proyecto por lo que en 1958, le retira el encargo del campus (Schulze, 1985) y deciden, de manera arbitraria, que algunos edificios del campus fueran construidos por otros arquitectos. Mies tiene 78 años de edad. Se pierde, con esta decisión, una posibilidad histórica que la arquitectura lamentará para siempre.

(a)

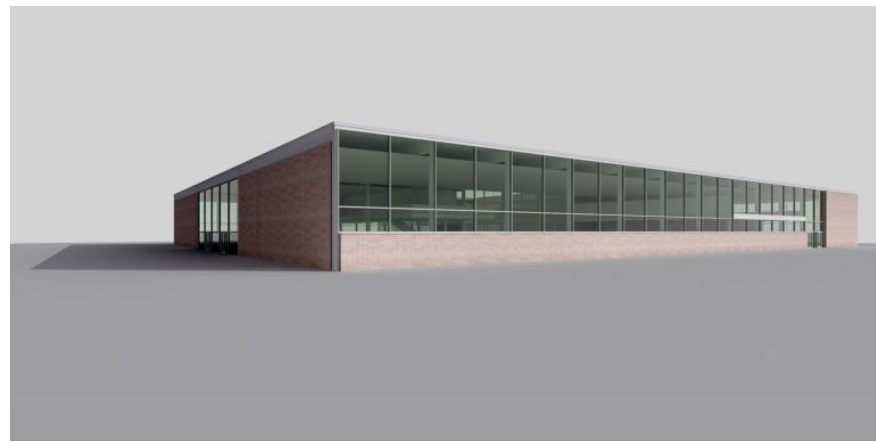

(b)

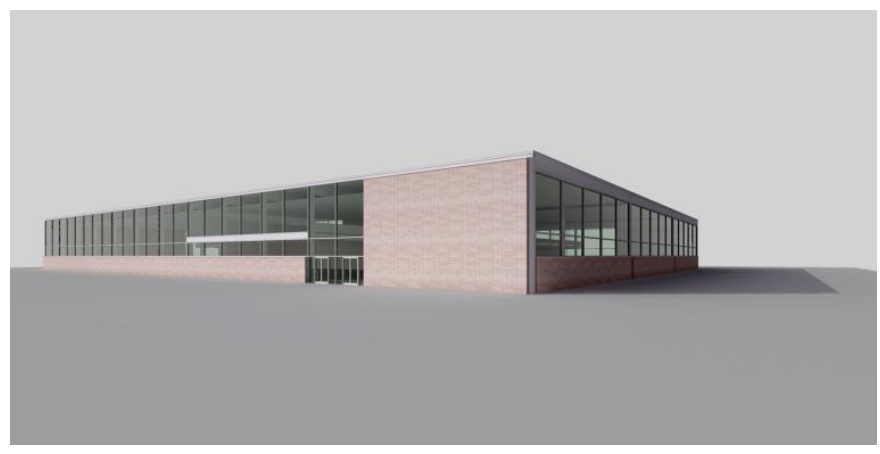

(c)

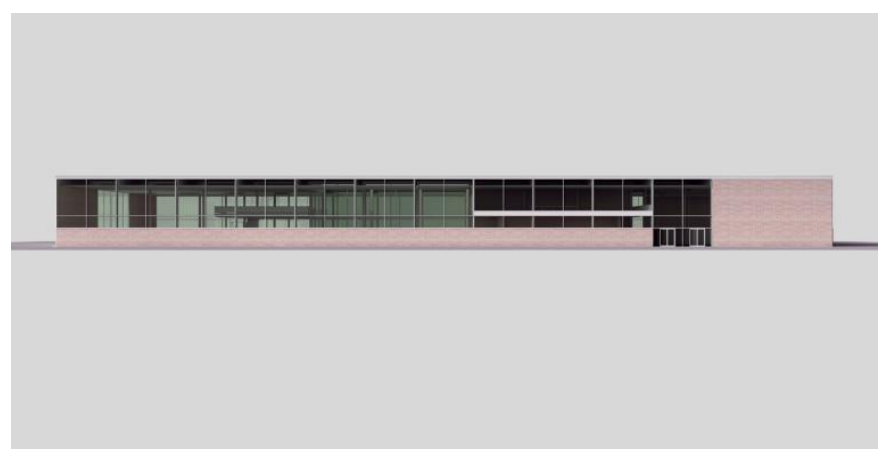

Imagen 1. El Edificio del Library and Administration Building, Illinois Institute of Technology: (a) Esquina Sureste, (b) Esquina Noreste y (c) Alzado Oeste.

La abundancia poco común de material gráfico del edificio del Library and Administration Building (Imagen 1) (870 hojas, de los cuales 483 han sido publicadas en el volumen 9 del Archivo Mies van der Rohe, editado por la Garland) nos habla de la importancia que Mies da a este proyecto y del rigor con que lo aborda. La importancia de este edificio se confirma cuando se estudia la exposición retrospectiva de la obra de Mies en 1947 en el Museo de Arte Moderno de Nueva York, diseñada por Mies y a cargo de Philip Johnson, en donde aparece un modelo a escala 1:1 de la esquina Sureste de este edificio. Cabe recalcar que desde 1944 modelos a escala 1:1 prácticamente reemplazan 
a los dibujos convencionales. Los modelos se empiezan a utilizar conjuntamente con dibujos a esta misma escala cuando Mies está trabajando y diseñando las conexiones del acero para el Library and Administration Building (Lambert, 2001).

Cuando se empieza a proyectar este edificio, se lo emplaza en la parte central del campus y, en su proceso de diseño, siempre se tiene en cuenta el futuro contexto construido. El edificio está pensado para albergar la zona de Administración general y la Biblioteca. Este programa funcional se soluciona en un único volumen monolítico con un eje de simetría en el sentido longitudinal y con un patio interior que se evidencia ya desde los primeros dibujos. Aunque el número de ejes estructurales en el sentido longitudinal y transversal, varía con el avance del proyecto, la posición y tamaño del patio permanece inalterable. Este espacio abierto en el corazón del edificio permite iluminar el interior y se convierte en el elemento organizador: en su legalidad intrínseca. A la par de la existencia del patio se aprecia una bodega de libros de igual tamaño. El patio interior y la bodega de libros se convierten en elementos que dan orden al conjunto. El patio abre el edificio al exterior, dando luz y ventilación natural. La bodega, adyacente por uno de los lados al patio, es idéntica, pero cerrada. En el sentido longitudinal el edificio está dividido en tres franjas que, al interior, están remarcadas por un cielo raso falso que también forma tres planos horizontales, separados entre sí por las columnas interiores. La fuerza de estas tres bandas se ve atenuada por cuatro franjas transversales definidas por el vestíbulo principal, el patio interior, la bodega de libros y la sala de lectura: la estructura y la distribución interior están íntimamente relacionadas.

El edificio tiene una serie de elementos que se combinan dando movimiento y fluidez al espacio interior: una plataforma en voladizo flotando en un espacio interior grande, un forjado intermedio conectado directamente con la carpintería, el contraste entre dos espacios de igual tamaño, el uno, el patio interior, abierto hacia el cielo, y el otro, la bodega de libros, cerrado y rehundido en el suelo. La manera neo plástica de organizar los espacios se evidencia en los numerosos bocetos previos a la propuesta final. El aprendizaje de la planta libre en sus proyectos europeos se manifiesta en este proceso. Los mismos criterios que utiliza para organizar el espacio público, los aplica ahora para organizar el espacio interior. En la definición de las plantas Mies van der Rohe demuestra, una vez más, su magistral habilidad para encontrar las estructuras organizadoras que den orden al conjunto.

Para definir el detalle del edificio del Library and Administration Building se observan detenidamente los dibujos originales de Mies van der Rohe y se redibuja todo el proceso, primero en dos dimensiones, para comprobar medidas y elementos utilizados, y luego en tres dimensiones, para darle materialidad, utilizando para ello los recursos informáticos necesarios. Se eligen todas las zonas en donde se producen transiciones entre materiales y de esta manera se entiende por qué Mies desecha algunas soluciones a favor de otras. Es en el análisis del proceso en donde verificamos la hipótesis: el detalle intensifica la forma. La calidad de los detalles depende no sólo de la técnica sino ante todo de su perfección arquitectónica. El escenario de estos detalles siempre es el edificio en su conjunto que, a su vez, se ve reflejado en cada uno de sus detalles. Mies van der Rohe siempre diseña uniones y nunca elementos aislados: crea relaciones constructivas esenciales.

Sólo 8 dibujos de los 483 publicados en la Garland sobre el Library and Administration Building tienen fecha. Dos de estos, el 731.63 y el 730.63, de acuerdo a la numeración del Museo de Arte Moderno, llevan la fecha de 1944. En el dibujo 731.63 se sintetiza el sistema constructivo de todo el edificio y se hace evidente la relación entre estructura y cerramiento en cada una de las fachadas. En el 730.63 se ve la perspectiva de la esquina Sureste en donde los materiales del edificio se vuelven evidentes (Imagen 2). Todo lo que Mies realiza tiene un objetivo visual, esto sucede también con el punto de vista elegido para esta perspectiva al dibujar el ladrillo sin la junta vertical para reforzar la horizontalidad del plano.

El lugar en donde un material se encuentra con otro se resuelve introduciendo un "reveal" o junta constructiva y visual: un pequeño espacio que permite el encuentro entre los diferentes materiales y además posibilita su articulación. Este es un espacio neutral en donde el movimiento, debido a las características físicas de cada material, y las inexactitudes de fabricación, preparación o montaje se soluciona convenientemente (Carter, 1974). Mies utiliza el "reveal" especialmente para unir dos materiales diferentes como ladrillo y acero, en cambio, en la unión de materiales iguales, como acero con acero, la junta es invisible. El uso de "capas" en el diseño le permite a Mies alcanzar altos niveles 
de precisión. Las "capas" están colocadas a distintas profundidades, cada una es una "corteza" independiente al igual que las "cortezas" de una cebolla.

(a)

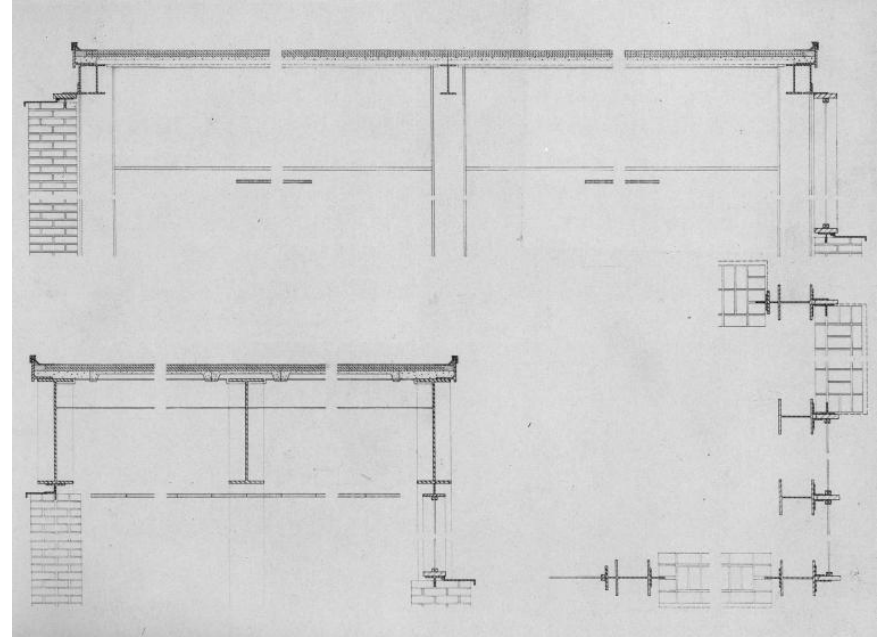

(b)

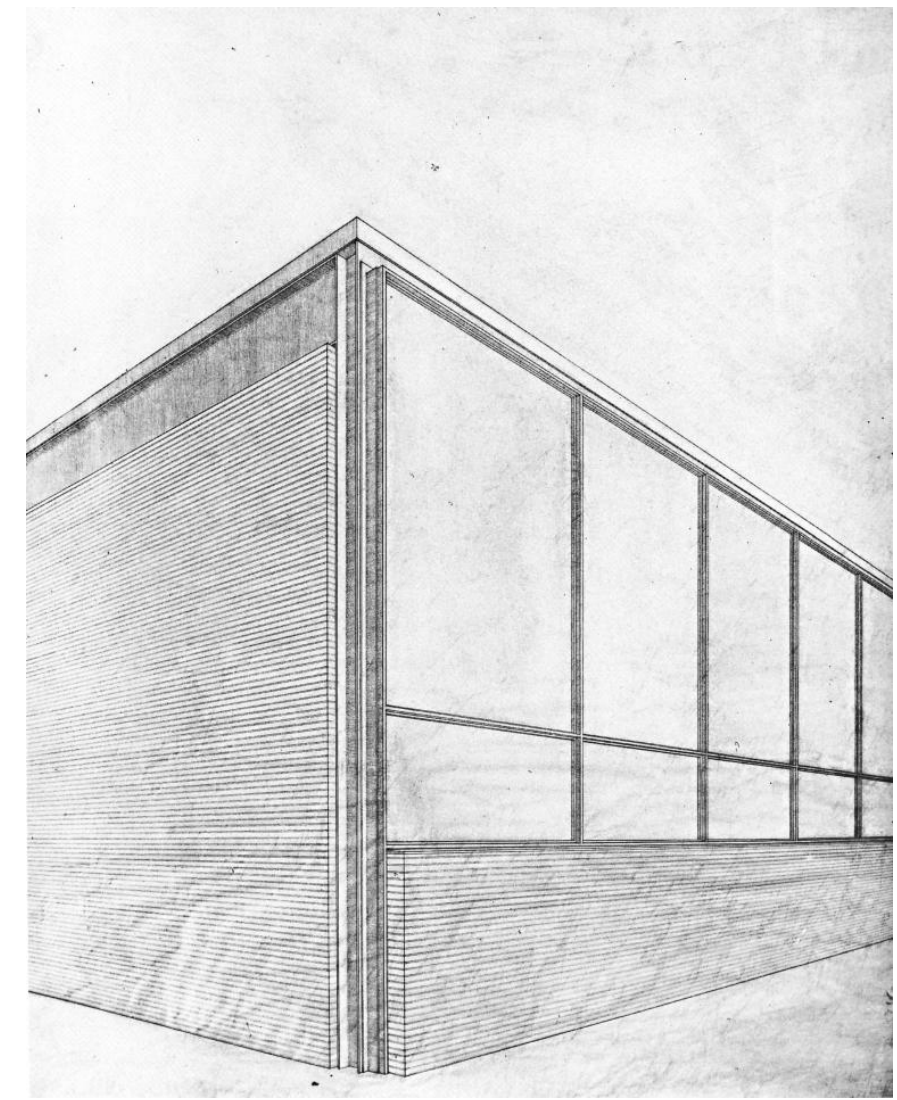

Imagen 2. Sección, planta constructiva (a) y perspectiva (b) de la esquina Sureste del Library and Administration Building.

Mies perfecciona el sistema constructivo: define hasta el último detalle pues es el sistema constructivo el que sirve como estímulo para la actividad ordenadora del arquitecto. Sin embargo, la construcción no determina la configuración del objeto, sólo sirve de marco sistémico en el que actúa la propuesta formadora de quien proyecta. Parafraseando a Helio Piñón podemos afirmar que Mies sitúa al proyecto en el ámbito de lo visual: esto significa simplemente entender la naturaleza sensitiva de los juicios en que se basan las operaciones del proyecto. Mies convierte a la arquitectura en una representación de la construcción (Piñón, 2009). 
Al definir la estructura, para el Library and Administration Building, Mies van der Rohe toma algunas decisiones que, de una u otra manera, están presentes en obras anteriores y posteriores. Son de la esquina Sureste la mayor parte de los dibujos de detalle de este proyecto por lo que podemos afirmar, sin temor a equivocarnos, que la estructura se empieza a detallar por aquí. Se propone la hipótesis de que se trabajaron cuatro etapas en el diseño del detalle: siendo la cuarta la última y final. La primera y la segunda solución tienen pocos dibujos, por lo que se asume que Mies dedica poco tiempo a su desarrollo. En cambio de la tercera etapa se encuentran muchos bocetos, dibujos técnicos y perspectivas de todos los puntos de transición de la planta. Para llegar a la solución final de la esquina Sureste, Mies van der Rohe explora varias relaciones previas que nos muestran a un arquitecto, en ocasiones dubitativo y, sobre todo, a un hombre que necesita realizar pruebas visuales para encontrar la solución idónea frente a un problema de construcción formal. Esta manera de trabajar se repite en todos los puntos de transición entre materiales: cuando se encuentra la solución idónea esta se adapta para las circunstancias específicas de la estructura y el cerramiento en cada punto. La cuarta y última etapa es sin duda la que más dibujos presenta, a la que más tiempo dedica. Cabe remarcar que el objetivo de esta metodología es netamente didáctico y no deja de ser sólo una aproximación al proceso que Mies adopta en la búsqueda de la solución más universal (Imagen 3).

\subsection{Primera etapa}

La primera etapa se desarrolla en la esquina Sureste y en la transición entre la columna y el cerramiento en el alzado Este. La columna es el elemento de transición entre el plano del alzado Sur y el Este, perpendiculares entre sí. Un perfil $\mathrm{HE}^{1}$ marca el inicio del plano Este. La planta, sección y simulación nos permiten entender la relación entre la solución técnica y la visual (Imagen 3(a)).

\subsection{Segunda etapa}

En esta etapa el arranque del plano del alzado Este se da a través de dos ángulos de lados desiguales, con puntas recortadas, relacionados con dos perfiles UPN ${ }^{2}$ (Imagen 3(b)). Uno de los ángulos forma el marco de la carpintería. Se prueba esta solución también en el punto de transición entre la columna y el muro en el alzado Este. En cierto momento se propone utilizar una HE en lugar de los ángulos y las UPN. En la perspectiva se ve que la solución no es del todo solvente pues no independiza visualmente a cada uno de los elementos. Además, en la perspectiva se verifica que los perfiles del arranque del plano llegan hasta el goterón superior y se entregan directamente al perfil de la cubierta. La planta, sección y simulación nos muestran la relación entre la solución técnica y la visual.

\subsection{Tercera etapa}

Esta etapa tiene dos momentos: en el primero el plano del alzado Este arranca con dos ángulos de lados desiguales relacionados con dos perfiles UPN con el marco de la carpintería formado por una barra de acero. En los puntos de transición entre la estructura y el cerramiento en el alzado Este, Sur y Norte también se ve la relación entre los perfiles UPN y los marcos de la carpintería. En el segundo momento se usa una IPN en lugar de las dos UPN: decisión más económica desde el punto de vista constructivo pero con similar efecto visual. Esta se desarrolla en la esquina Sureste y en los puntos de transición entre columna y cerramiento en el alzado Este, Sur y Norte. Se encuentran dibujos de la esquina Sureste, del alzado Este, del Sur, del Norte y del ingreso lateral en el alzado Este. El ángulo que sujeta el marco de la carpintería ya no llega hasta la cubierta, sino que gira 90 grados en la parte superior, convirtiéndose en una "capa" independiente. A la par que diseña una solución solvente desde el punto de vista constructivo, dibuja una perspectiva para comprobar su validez visual. Esta manera de proceder caracteriza la obra de Mies y he aquí su valor como arquitectura emblemática y ante todo formativa. Con la planta, sección y simulación (Imagen 3(c)) se verifica que la transición entre materiales, utilizando esta solución, es fuerte y marcada.

\footnotetext{
${ }^{1}$ Perfil HE: Perfil $\mathrm{H}$ de alas anchas

${ }^{2}$ Perfil UPN: Perfil U de alas inclinadas
} 
MASKANA, Vol. 3, No. 2, 2012

(a)
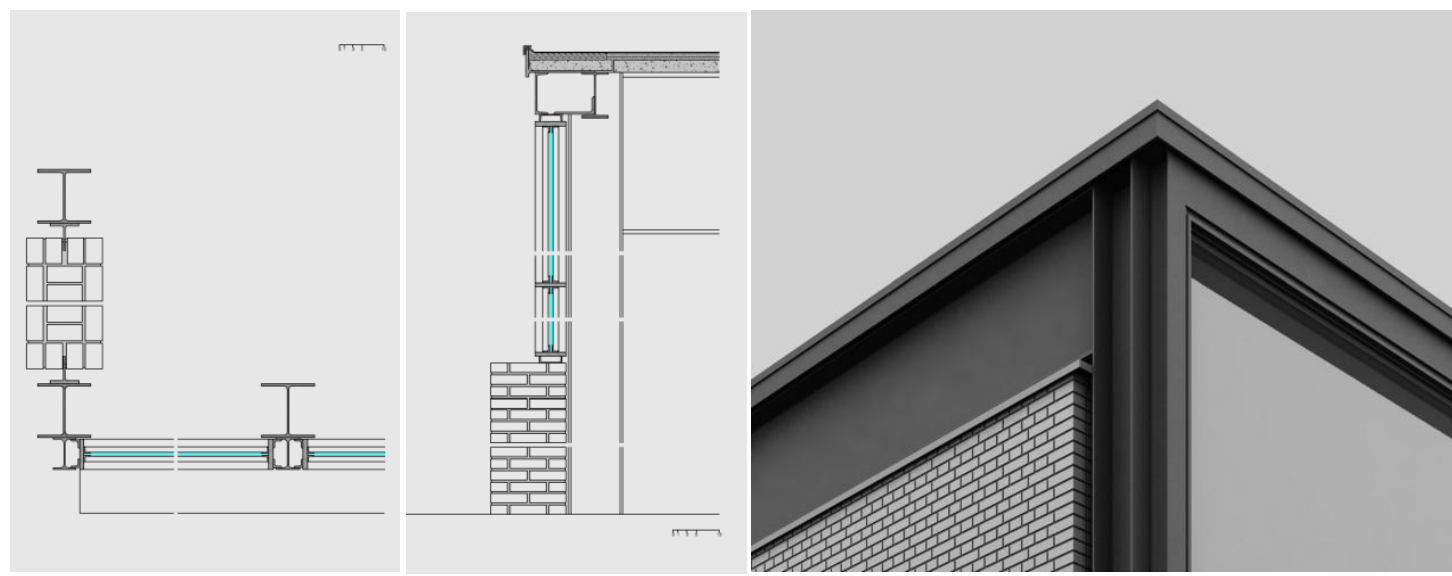

(b)

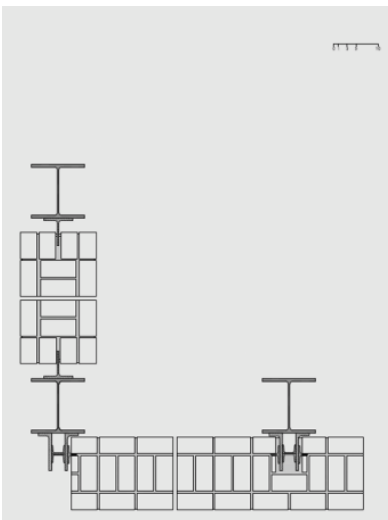

(c)
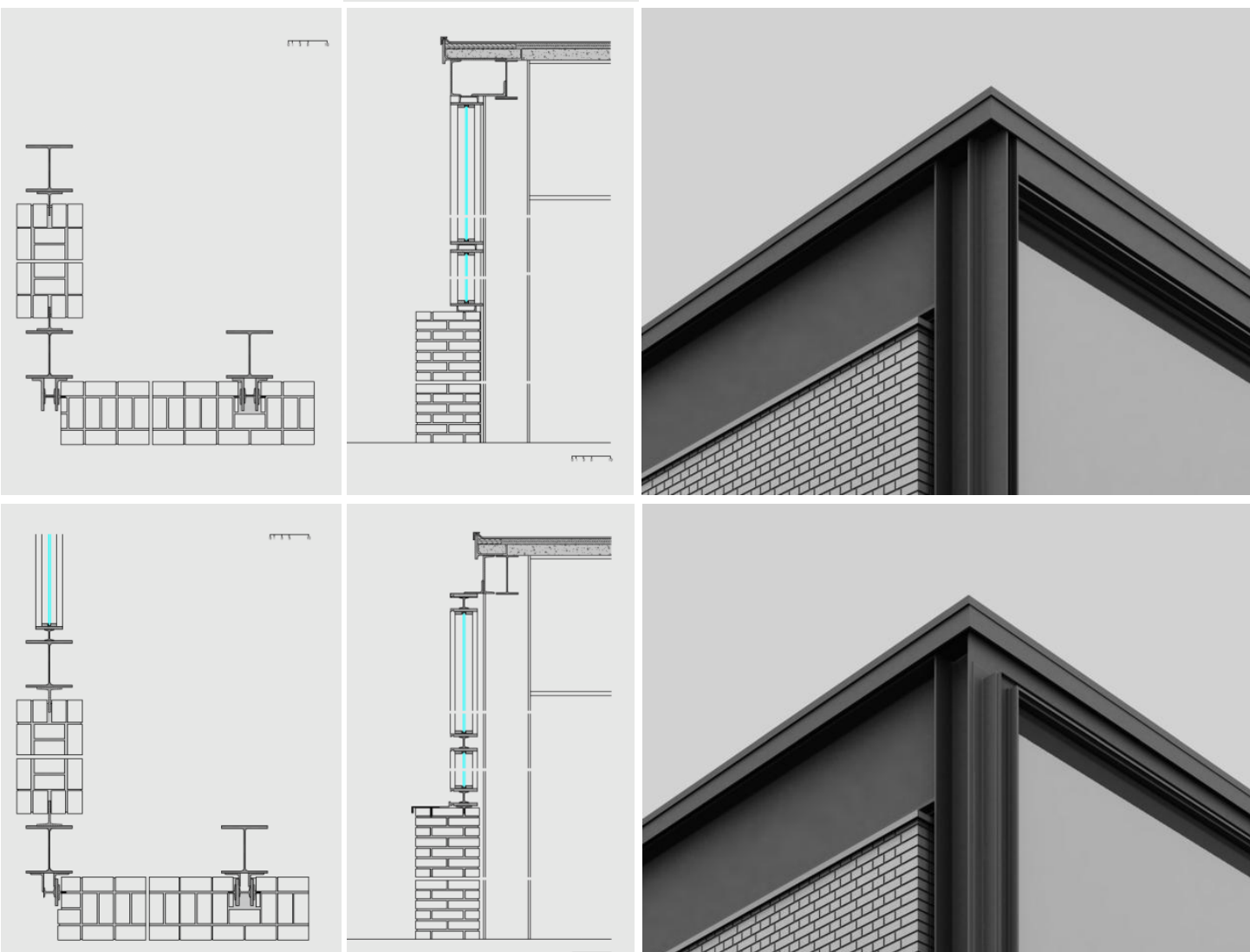

(d)
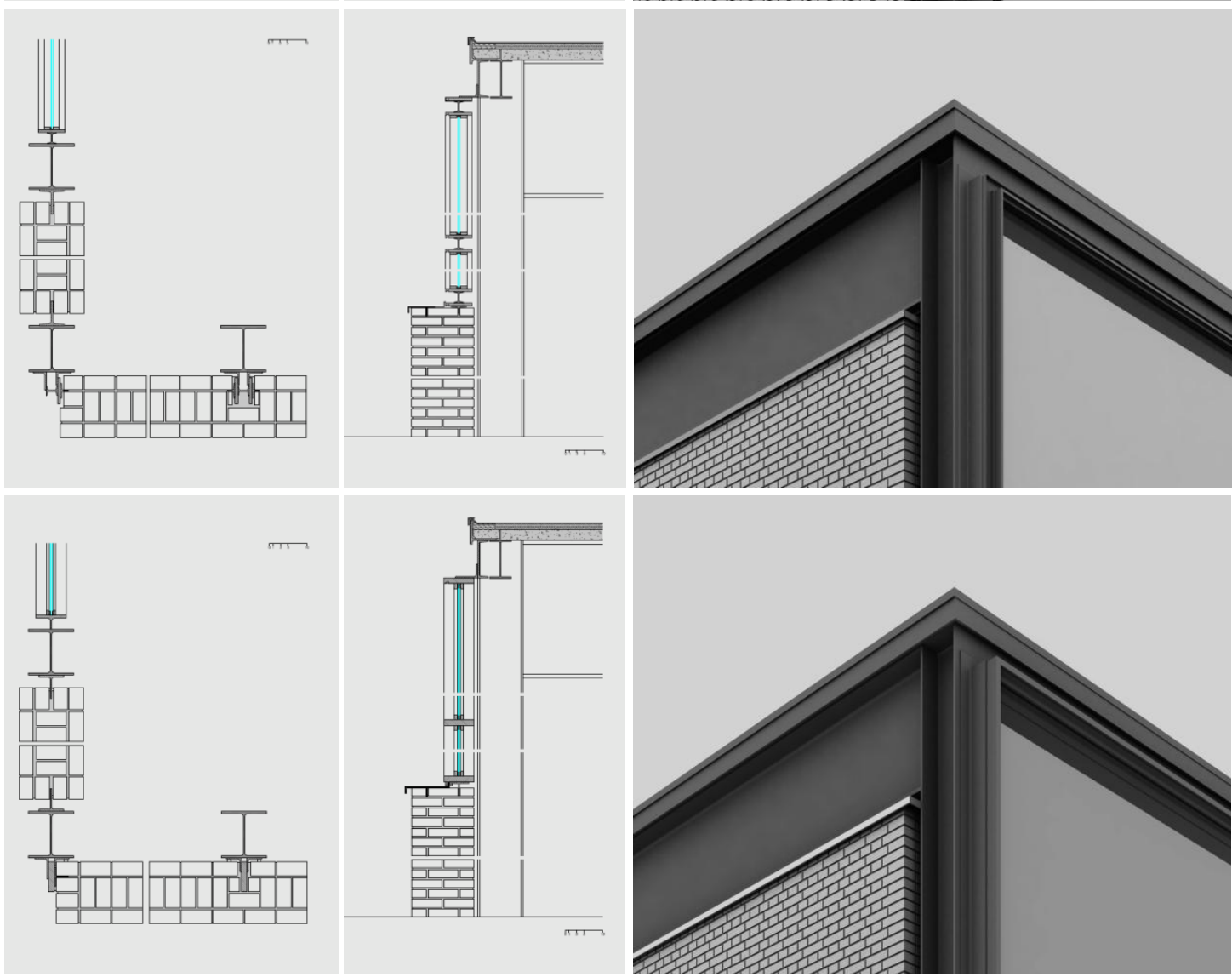

Imagen 3. Planta constructiva y perspectiva de la esquina Sureste del Library and Administration Building: etapa 1 (a), etapa 2 (b), etapa 3 (c) y etapa 4 (d). 


\subsection{Etapa final}

A más de la esquina Sureste, en esta etapa, se encuentra la solución para todos los puntos de transición entre materiales. Trece en total, en donde a más de la relación estructura cerramiento se estudia la colocación del ladrillo. Al acercarse a la solución final Mies opta por utilizar una HE cortada cuya alma se ve como una línea delgada hacia el alzado Este. La HE cortada se suelda a dos IPN que sujetan las barras metálicas. En el mismo dibujo Mies propone una solución más sensata: dejar la HE cortada como marco de la carpintería y eliminar los perfiles IPN. En un paso intermedio sujeta la estructura con ángulos de lados desiguales con bordes cortados unidos entre sí por dos platinas de sección cuadrada. En el mismo boceto se prueba la opción de soldar directamente las barras a la HE cortada, de forma que la transición entre un elemento y otro sea una línea más sutil. Posteriormente se cambia la HE cortada por dos ángulos de lados desiguales de manera que la línea que separa los dos marcos sea más ancha. Junto con el detalle en planta se dibuja un alzado para dar cuenta del efecto visual de la solución.

El eslabón que nos lleva a la solución final aparece cuando reemplaza la HE cortada por una barra de acero sujeta por dos ángulos. Visualmente esto es fundamental pues la barra queda libre y el ángulo se convierte en otra capa que añade intensidad al detalle. En la medida que se llega a la solución final en planta también se trabaja la sección. Se estudia la transición entre las vigas de borde y el marco de la carpintería, así como el uso del goterón y su sujeción. El goterón provoca una sombra interesante que intensifica las relaciones: un detalle bien solucionado y riguroso intensifica las relaciones entre los materiales. En perspectivas a mano alzada comprueba la validez del uso del ángulo como elemento para el arranque del plano y la independencia visual y constructiva que éste da a la carpintería. Se estudia, también, la transición entre el marco de acero y el vidrio, así como su sujeción. Se prueban distintas uniones cuyos efectos visuales varían rotundamente. La diversidad de posibilidades nutre el conocimiento de la manera de proceder de Mies van der Rohe. Algunas soluciones no son del todo solventes, ni desde el punto de vista constructivo ni desde el visual. Este proceso nos conduce a la solución final (Imagen 3(d)) en donde la barra de acero es el marco de la carpintería y está sujeta a la estructura a través de dos ángulos de lados desiguales. Es la propuesta más económica, rigurosa y universal. La columna permite la transición entre los planos del alzado Este y Sur, el ángulo marca el inicio de la carpintería y una HE cortada relaciona la estructura con el muro de ladrillo permitiendo movimientos diferenciales de cada material.

En la sección transversal (Imagen 4(d)) se utiliza una HE cortada como transición entre estructura y cerramiento. El goterón provoca una sombra que intensifica la calidad de la solución. En la solución final del remate de la sección transversal, un ángulo de lados desiguales, con uno de sus bordes cortados, sujeta al marco de la carpintería que se encuentra en un plano anterior al del ángulo. Se usa una HE cortada y un ángulo para recibir el forjado y al mismo tiempo proteger al alzado del agua. En la sección longitudinal (Imagen 5(b)) se relaciona la viga $\mathrm{IPE}^{3}$ con el muro de ladrillo a través de una HE cortada. Este espacio de transición permite un buen funcionamiento constructivo y visual del conjunto. El goterón se sujeta en la parte inferior de la HE cortada y, a más de proteger al muro contra el agua, genera una línea de sombra. En la parte superior, la HE cortada sirve para recibir al forjado. El ángulo de remate, a más de sujetar la tela asfáltica, arroja sombras y es una capa que da mayor calidad a la arquitectura. En la sección longitudinal también se verifica que el cielo raso queda despegado de la viga estructural IPE. En el encuentro entre columna y muro de ladrillo se usan dos ángulos de lados desiguales que sujetan a una barra que sirve de marco de las carpinterías. Visualmente es una línea del grosor justo para pautar la carpintería de acuerdo a la escala del edificio. El vidrio se sujeta con platinas rectangulares lo suficientemente anchas como para sujetarlo de manera solvente. La relación entre la estructura, el muro y la carpintería, con el ingreso principal, en el centro del alzado Sur, se da con una HE cortada. La estructura queda vista y está en el mismo plano que el cerramiento por lo que pauta la fachada.

El proceso de investigación arroja nuevamente a la imagen de la esquina Sureste (Imagen 2(b)), se descubre que su existencia no es casual, es fruto de meses de trabajo y de concepción rigurosa. Una vez Mies van der Rohe tiene clara la solución del detalle la aplica a todos los restantes puntos de transición entre materiales. Es interesante comprobar que mientras más clara es una solución, tanto

\footnotetext{
${ }^{3}$ Perfil Viga IPE: Perfil estructural en sección "I"
} 
constructiva como visual, más interés tiene. En este sentido, aquella propuesta que más se acerca a los atributos del nuevo arte es la que prevalece: esto no es una decisión racional, en ella juegan un papel determinante los sentidos y, en este caso, básicamente la mirada.

\section{APROXIMACIÓN VISUAL AL PROYECTO DEL LIBRARY AND ADMINISTRATION BUILDING}

Con los detalles definidos se busca tener una experiencia visual del Library and Administration Building (1944-1945) (Imagen 1), a sabiendas de que el edificio nunca se construye. Se quiere identificar la relación forma-programa: la descripción visual de las respectivas estructuras, el reconocimiento de la tensión que las vincula, el sistema estructural, la relación con la estructura espacial del edificio, la relación estructura-cerramiento, los sistemas, materiales y texturas que aparecen en el proyecto, combinando el material original con la representación digital. Se ha demostrado que el detalle en el Library and Administration Building tiene cuatro etapas, ahora se pretende mostrar como Mies, una vez encuentra la relación idónea entre materiales, la aplica con coherencia en todos los puntos de transición entre materiales. "La (re)construcción del proyecto se basa en el reconocimiento de la tensión entre el material y los criterios de forma que lo estructuran, a partir de la conciencia de su condición formadora, estructurante, ordenadora... Se trata de sumergirse en el sistema de valores de su arquitectura y de sus criterios de proyecto, para conocerla desde su interior, inmersión que exige -y, a la vez, desarrolla- la capacidad de reflexión visual y tiende a extender los principios básicos del proyecto a situaciones alternativas... quien se enfrenta a un edificio para conocer sus valores y (re)construir su arquitectura, dispone de un marco coherente -el del edificio- en el que cualquier episodio traduce un criterio formal y, a la vez, adquiere sentido estético... el énfasis en la visión directa de la obra -o de su descripción gráfica- permite reconocer la condición estructural del programa: la propia identidad arquitectónica de la obra estriba en la compatibilidad de su orden espacial con la estructura orgánica de las actividades a que se destina el edificio. El programa aparece así como un ente ordenado, cuya estructura es revelada por la propia constitución del objeto" (Piñón, 2005).

Se exploran 5 zonas que nos permiten tener una visión global del proyecto, sabiendo que el proyecto tiene un eje de simetría en el sentido longitudinal. Nos sumergimos en cada zona para, a partir del detalle, entender el espacio interior y exterior, y comprobar que cada decisión en planta o sección implica un resultado visual que debe ser evaluado.

En la Zona 1 se encuentra la esquina Sureste que es el punto de relación entre tres planos: el alzado Este, el Sur y la cubierta (Imagen 4(a)). En el alzado Este la estructura está detrás del cerramiento formado por un antepecho de ladrillo visto y una carpintería de acero y vidrio. La modulación de la fachada va de acuerdo con la modulación general de la estructura. En el alzado Sur la estructura está en el mismo plano que el cerramiento y pauta la fachada. Las dos crujías laterales del alzado Sur son planos opacos de ladrillo visto y la central es una carpintería de marcos de acero y vidrio en donde se encuentra la entrada principal al área de Administración. Dibujos, como estos, en donde se muestra la planta y la sección constructiva, asociada a su alzado parcial son frecuentemente usados en la oficina de Mies van der Rohe. En la simulación del detalle de la esquina Sureste (Imagen 4(c)) se observa la relación entre la columna de acero y los dos planos perpendiculares. El plano del alzado Este se superpone a la columna mientras que el plano del alzado Sur está en el mismo eje y se relaciona con la columna a través de un perfil que sirve de transición visual entre un elemento y el otro. La distinta función visual de la estructura en la fachada Este y Sur se constata en el dibujo de la planta constructiva (Imagen 4(b)). La relación entre la estructura y los cerramientos es un tema que demanda especial atención a la oficina del arquitecto. En la sección transversal (Imagen 4(d)), se observa cómo el cerramiento se superpone a la estructura y se sujeta con un ángulo similar al de la planta. El cerramiento tiene dos partes: en la parte superior un plano transparente corrido a lo largo de prácticamente toda la fachada, formado por la carpintería de acero y vidrio; y, en la parte inferior, un plano opaco de ladrillo visto. Un perfil HE cortado permite independizar visualmente a cada uno. 
Estos planos corridos le dan mayor horizontalidad al proyecto. Hacia el interior, en la perspectiva dibujada en el despacho de Mies van der Rohe (Imagen 4(e)), se observa la relación entre la estructura

(a)

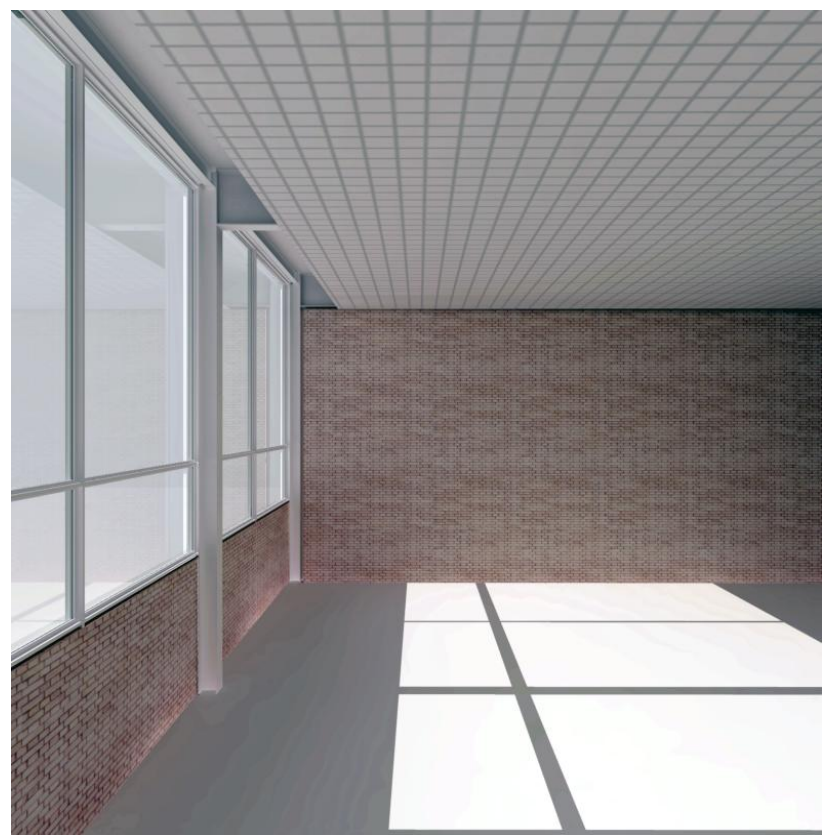

(b)

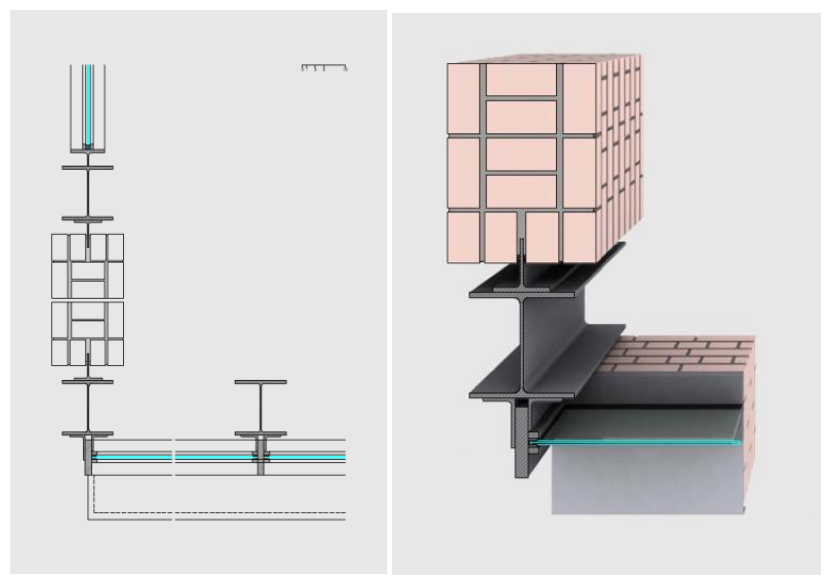

(c)

(d)

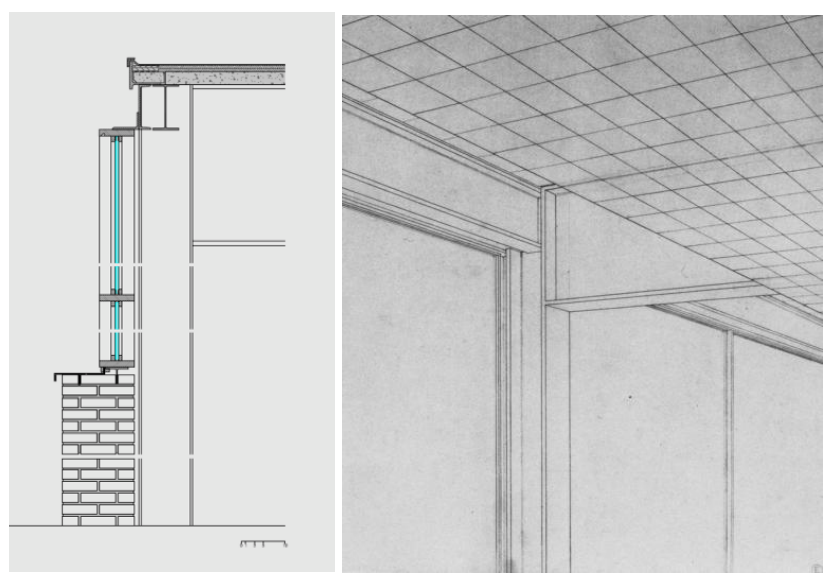

(e)

Imagen 4. Espacio interior de la esquina sureste (a), planta constructiva de la esquina Sureste (b), simulación del detalle de la esquina Sureste (c), sección constructiva transversal en el alzado Este (d) y relación entre estructura y cielo raso al interior en el alzado Este (e). 
y el cielo raso que, a más de estar separado de la viga estructural IPE, está separado del eje de las columnas, transformándose en un plano independiente. La viga IPE se cierra para formar una caja que se relaciona con el ala de la columna. La columna se asienta directamente al suelo y permite que el plano de ladrillo se deslice delante de ella relacionándose con éste a través de un perfil o transición constructiva. Dejar la estructura vista es posible cuando la construcción es precisa y de alta calidad. En la simulación (Imagen 4(a)) se ve el espacio interior que la esquina construye, se verifican las relaciones entre elementos estructurales, cerramientos y cielo raso, así como la incidencia de la luz natural sobre el espacio.

En la sección longitudinal (Imagen 5(b)) se observa la relación entre la viga estructural y el plano de cerramiento del alzado Sur que está en su mismo eje. El cerramiento Sur tiene 3 crujías: las dos laterales son opacas con ladrillo visto de piso a techo y la intermedia transparente en donde se ubica la entrada principal al edificio. En la perspectiva interior (Imagen 5(c)) se verifica que la decisión de independizar el cielo raso y por ende dejar vistos los elementos estructurales, implica mayor rigor constructivo. La posibilidad de identificar, con total claridad la propuesta estructural es parte de la propuesta del arquitecto para este proyecto. Se observa siempre la presencia de un elemento de transición entre materiales diferentes. En la simulación (Imagen 5(a)) se ve el espacio interior del vestíbulo general inmediatamente a continuación del ingreso Sur. Este vestíbulo de doble altura permite el acceso a la zona de oficinas de administración y al mezzanine.

(a)

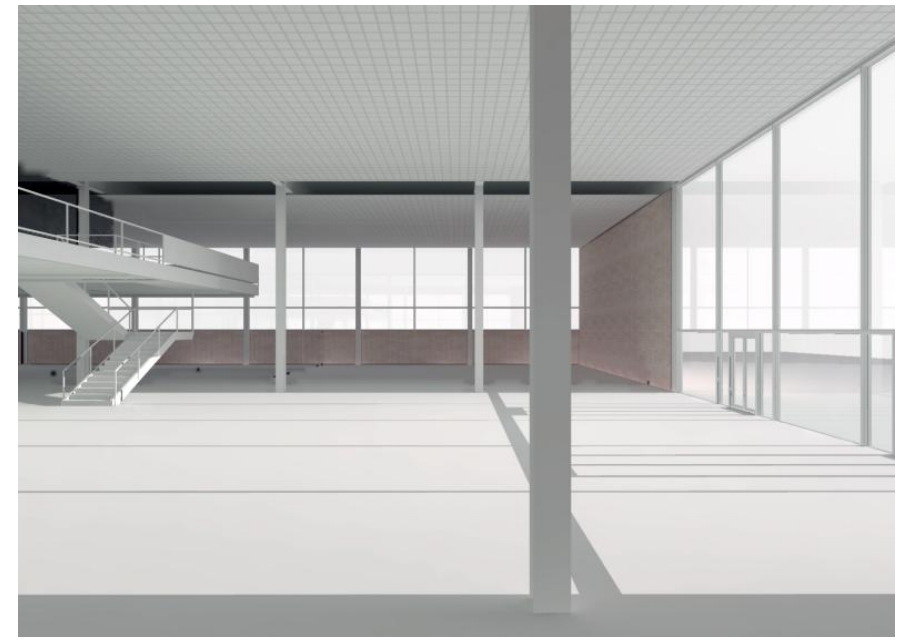

(b)

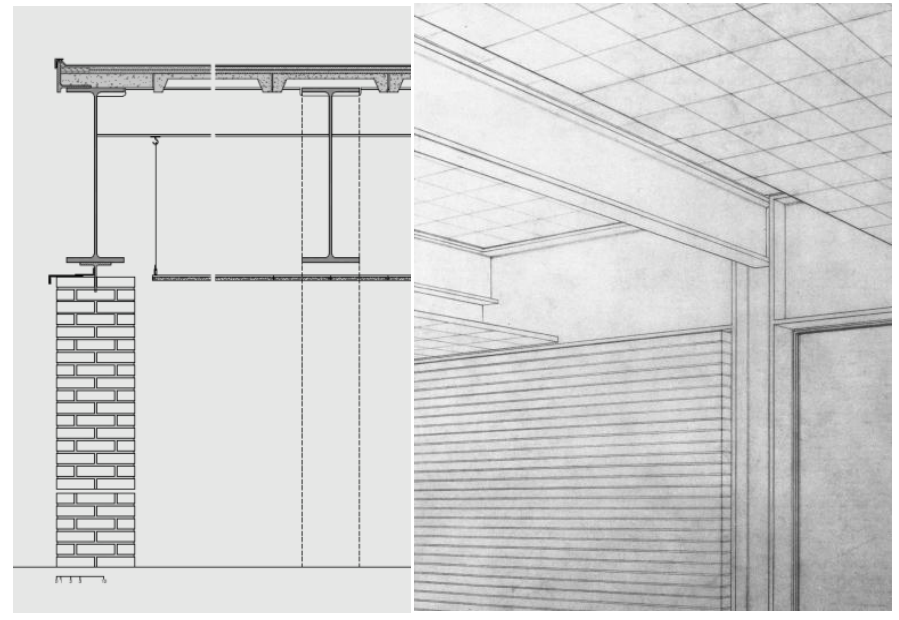

(c)

Imagen 5. Vestíbulo general con el ingreso principal a la derecha y el mezzanine a la izquierda (a), sección constructiva longitudinal en el alzado Sur (b), relación entre estructura y cielo raso (c).

En la Zona 2 se encuentra la esquina Noreste (Imagen 1(b)) que es el punto de encuentro de los cerramientos del alzado Norte, del Este y de la cubierta. El espacio interior que se aprecia desde la 
(a)

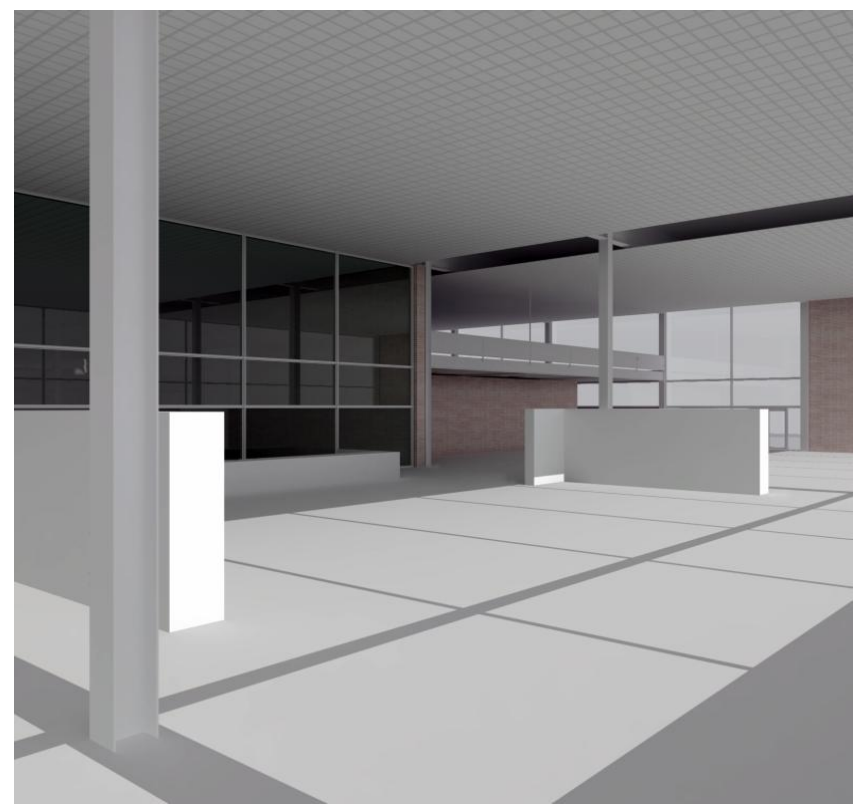

(b)

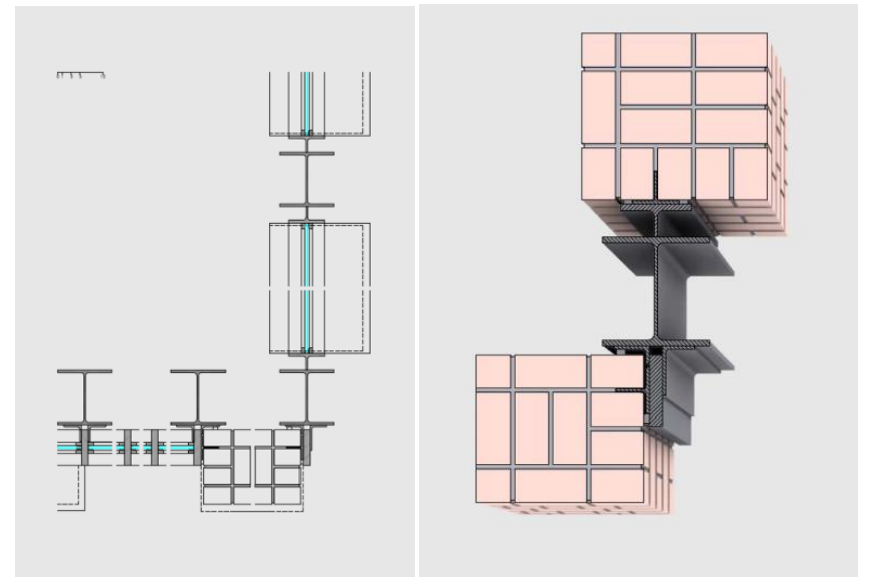

(c)

(d)

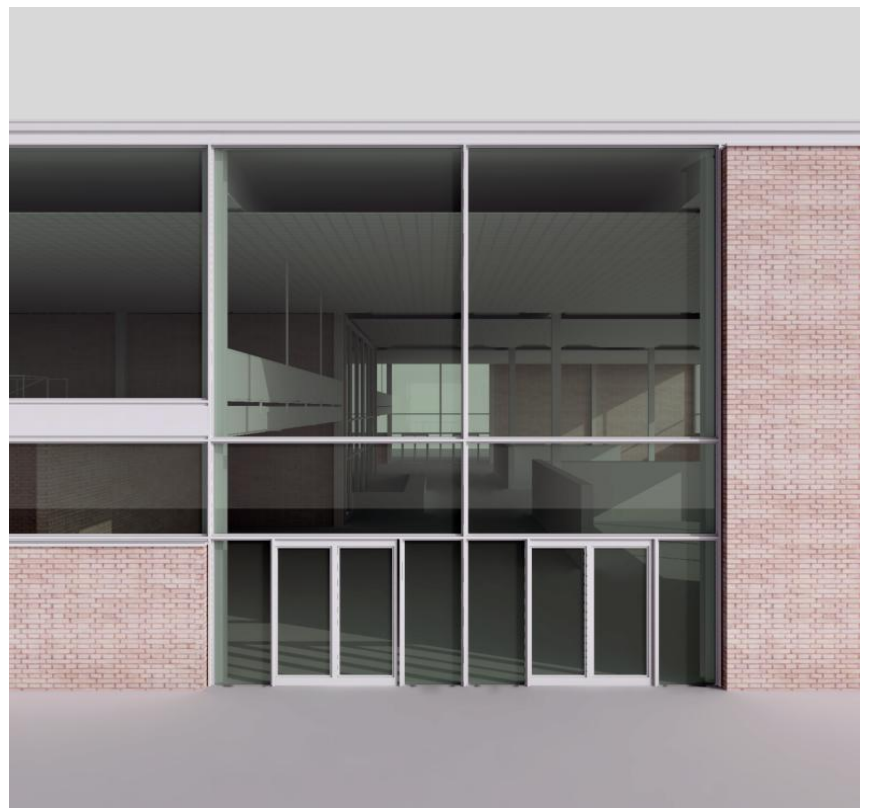

Imagen 6. Sala de lectura vista desde la esquina Norteste (a), ingreso a la sala de lectura y alzado Este parcial (b), planta constructiva de la esquina noreste (c), simulación de la esquina noreste (d). 
esquina Noreste (Imagen 6(a)) tiene doble altura y da cabida a la sala de lectura. Se construye con la relación fluida y no compartimentada de columnas (líneas) y libreros (planos) que se desplazan perpendiculares entre sí. A través de la planta constructiva (Imagen 6(b y c)) podemos comprobar que el alzado Norte tiene la estructura en el mismo plano que el cerramiento por lo que es visible desde el exterior y pauta la fachada. Está formado por tres crujías iguales, con un antepecho de ladrillo en la parte inferior y una carpintería de acero y vidrio en la superior. En el alzado Este la estructura está detrás del cerramiento: en el extremo Norte tiene un plano opaco de ladrillo visto desde el suelo hasta la cubierta y a continuación un plano transparente de carpintería de acero y vidrio con las puertas de acceso a la sala de lectura. La simulación (Imagen 6(d)) nos muestra la transparencia del plano y las particularidades del espacio interior. La solución final de la esquina Noreste mantiene similares relaciones, entre la estructura y el muro de ladrillo, a las estudiadas en la esquina Sureste (Imagen 4(b y c)) con la única diferencia de que el muro de ladrillo del alzado Norte tiene dos ladrillos y medio.

(a)

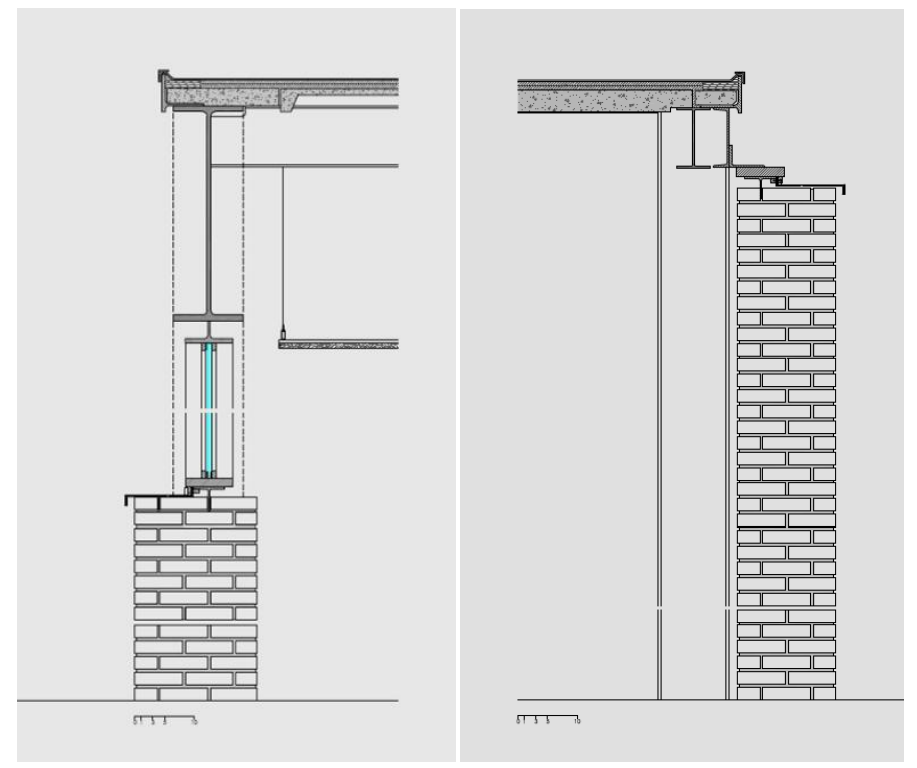

(c)

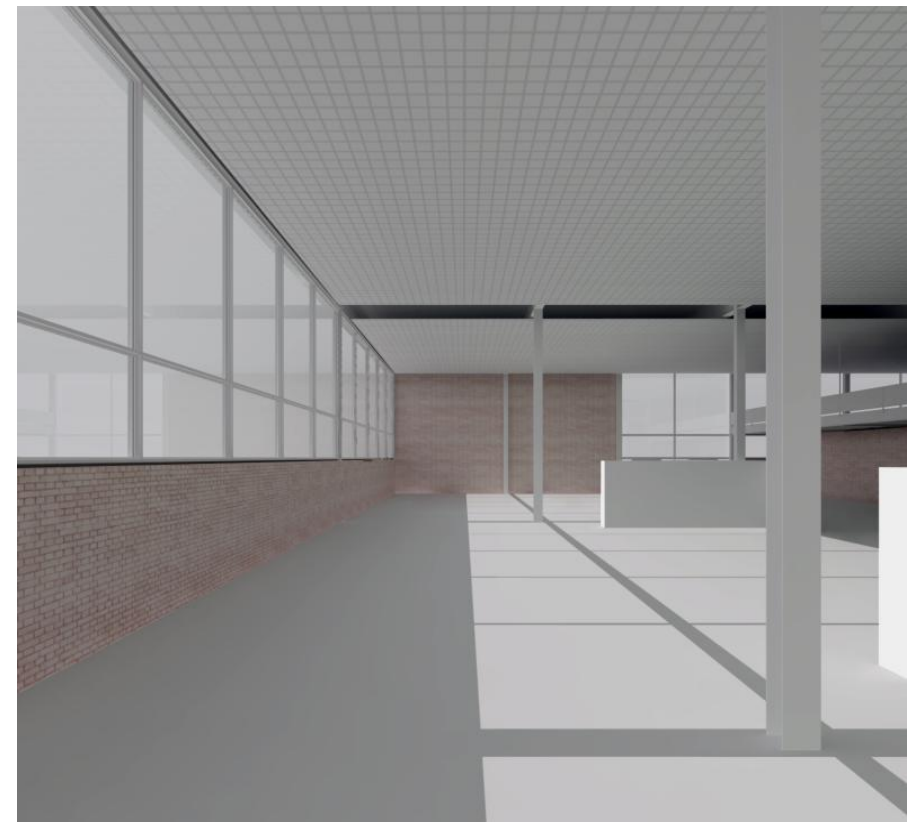

(b)

Imagen 7. Sección constructiva longitudinal en el alzado Norte (a), sección constructiva transversal en el alzado Este (b) y simulación del espacio interior con el alzado Norte a la izquierda (c). 
En la sección longitudinal, también de la esquina Noreste (Imagen 7(a)), el encuentro entre las carpinterías y el antepecho de ladrillo es similar al del alzado Este, con la diferencia de que en este se tiene un muro de dos ladrillos y medio. La presencia del goterón, a más de solucionar un problema de humedad, genera una línea de sombra que intensifica visualmente al conjunto. La HE cortada sirve de marco a la carpintería, a más de ser una transición visual entre elementos. En el remate, la HE cortada recibe al forjado y también cumple la función de goterón. El ángulo superior, a más de goterón, sirve para sujetar la tela asfáltica y generar una última línea de sombra. La viga IPE es el elemento de transición entre el plano vertical y el plano horizontal de cubierta: una transición a otra escala. Igual que en la sección de la esquina Sureste, el cielo falso cuelga desde las vigas y no toca la estructura ni la carpintería. En la sección transversal (Imagen 7(b)), la parte superior del marco de la carpintería se prolonga sobre el muro, la HE cortada también sirve para relacionar el marco con el muro y establecer una transición visual, a más de sujetar el goterón. El ángulo de lados desiguales sostiene la carpintería al igual que lo hace en otras partes del alzado Este. En la simulación (Imagen 7(c)) se observa el espacio interior de la esquina Noreste y la sala de lectura así como los antepechos de ladrillo y el plano transparente de acero y vidrio. Se ve, además, la importancia que los libreros tienen para ayudar a conformar el espacio continuo y fluido que caracteriza a este proyecto.

En la Zona 3 se encuentran las oficinas ubicadas en dos niveles. Hacia el alzado Este y Oeste, la viga de borde del forjado queda vista hacia el exterior (Imagen 1(c)). Desde los ingresos Este y Oeste se ven los dos niveles, (Imagen 8(a)), que contrastan con la sala de lectura de doble altura y completamente abierta. Para solucionar el encuentro, entre el forjado del segundo nivel de oficinas y el cerramiento exterior, se usa una UPN y una IPE que, juntas, forman la viga de borde (Imagen 8(b)). Los marcos de las carpinterías se relacionan con la UPN a través de dos UPN de menor dimensión que sirven de transición visual. Hacia el otro extremo, cuando la estructura de entrepiso se encuentra con el muro de la bodega de libros, se usa una IPE de dimensiones similares pero a diferencia de la solución en fachada el encuentro con el muro es más pobre: se sugiere utilizar hormigón y dejarlo parcialmente embebido en el muro (Imagen 8(b)). En las perspectivas se ve el efecto visual del ala inferior de la IPE (Imagen 8(c)). En la simulación (Imagen 8(d)) se muestra la relación entre el ingreso Este y la zona de dos niveles con el espacio continuo y no compartimentado característico en su obra.

(a)

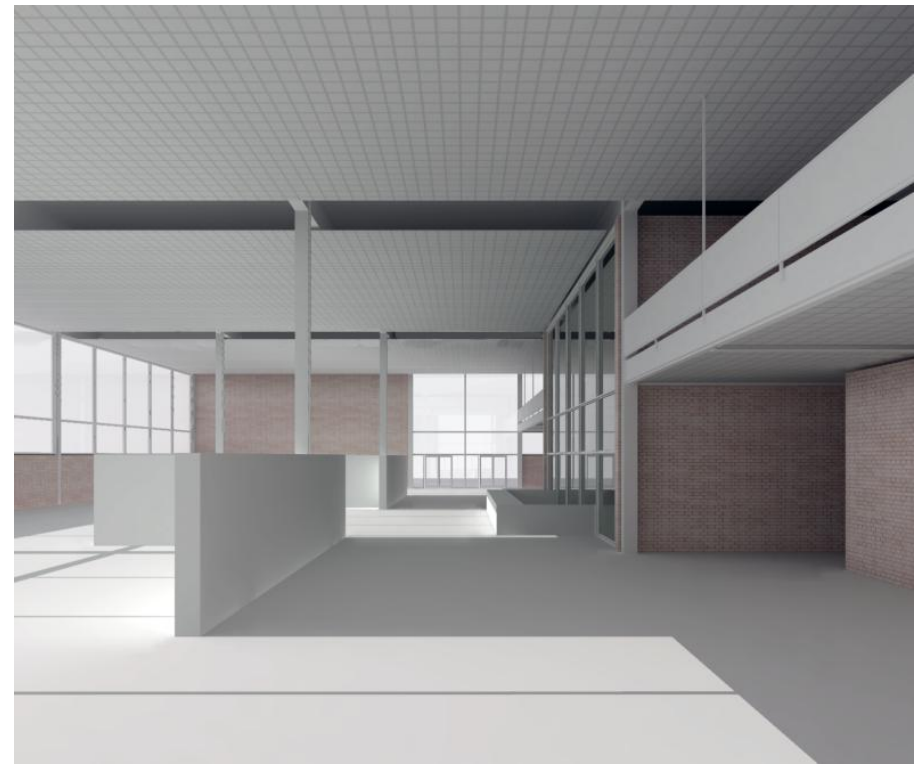

Imagen 8. Ingreso Oeste con la bodega de libros a la derecha y la sala de lectura a la izquierda (a), sección constructiva transversal en la zona de dos niveles (b), detalle del sala de lectura en donde se ve el ala inferior de los perfiles y división en tres partes cuando los módulos no pueden ser iguales (c) y vista de la zona de oficinas en dos niveles e ingreso a la sala de lectura (d). 
(b)

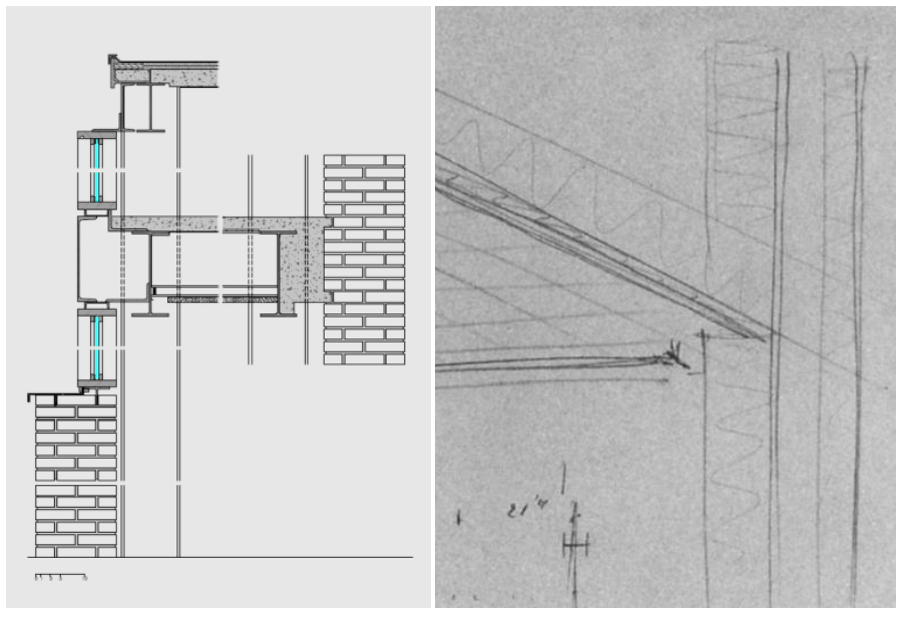

(d)

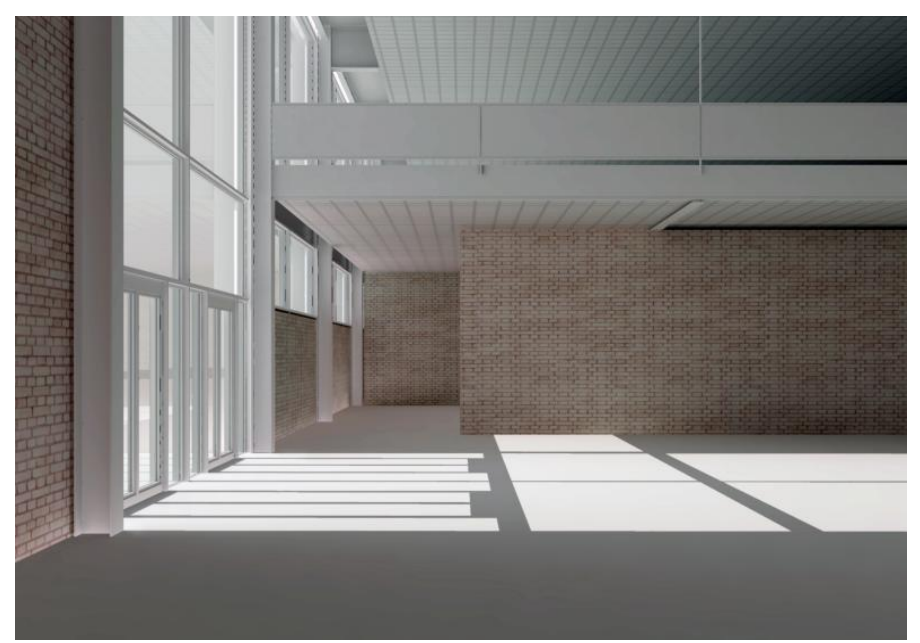

(c)

Imagen 8. (continuación)

En la Zona 4 se encuentra la bodega de libros que tiene un cerramiento transparente al Norte y tres muros ciegos al Sur, Este y Oeste; y tres niveles, uno de ellos en el sótano. Es uno de los centros del edificio, aquel que lo traba al suelo, y, junto con el patio, organiza los otros espacios como la sala de lectura y la zona de servicios y oficinas. En la perspectiva (Imagen 9(a)) se constatan todos los aportes espaciales de este proyecto: estructura vista, cielo raso independiente, relación entre espacios de una y dos alturas, solución entre estructura y cerramientos, concordancia entre planos transparentes y opacos, espacio fluido y libre creado a través de elementos efímeros de baja altura.

El muro de la bodega de libros se relaciona con la columna a través de una HE cortada que se convierte en la transición visual entre los dos, mientras que en el otro sentido el muro se relaciona con el plano Norte de la bodega con una HE cortada que es el marco de la carpintería (Imagen 9(b y c)). El muro está desplazado respecto del eje de la estructura: decisión que permite pautar el corredor con las columnas (Imagen 9(d)). Al liberar el cerramiento y la estructura se ve a la bodega como un volumen independiente: otra "capa" dentro del proyecto. El corredor es el espacio que vincula las dos zonas principales del edificio: hacia el Norte la biblioteca y al Sur la administración. El corredor, con sólo un nivel de altura, es un espacio en sombra que da ilación a dos espacios de doble altura más luminosos y abiertos.

En la Zona 5 se encuentra el patio (Imagen 10(a)) que, junto con la bodega de libros, son los centros del edificio: así como la bodega traba al edificio con el suelo, el patio la relaciona con el cielo. Se adosa con la bodega en su lado Norte, mientras que los otros tres lados son transparentes. En la solución final de la esquina del patio interior (Imagen 10(b y c)) se propone que, en el alzado Sur, el 
(a)

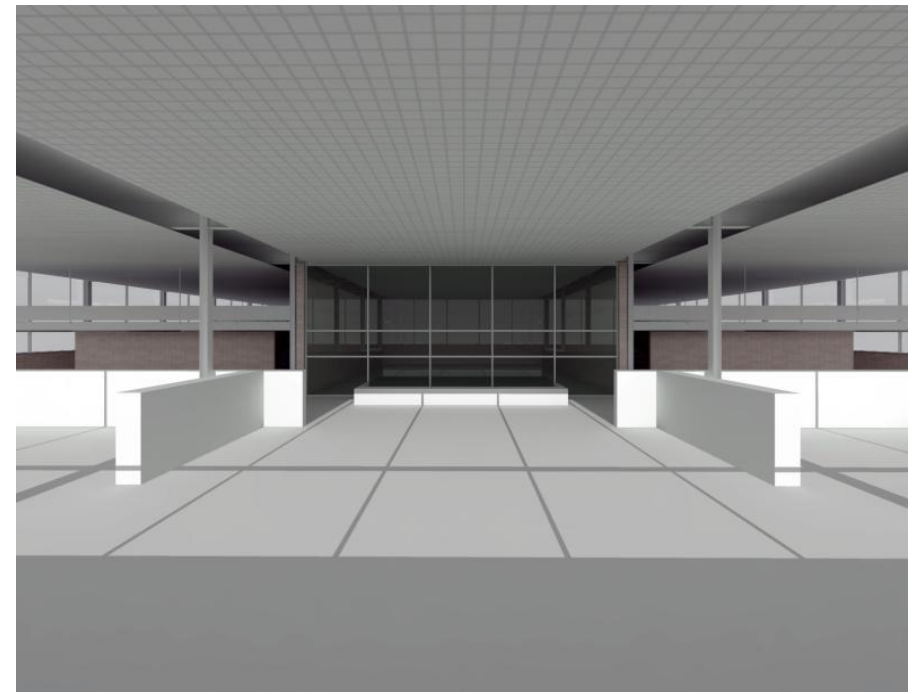

(b)

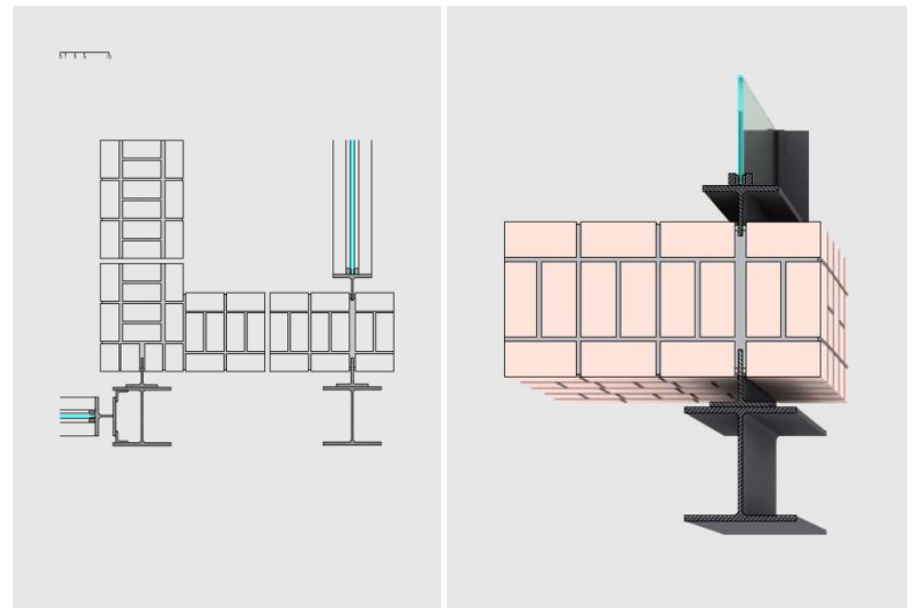

(c)

(d)

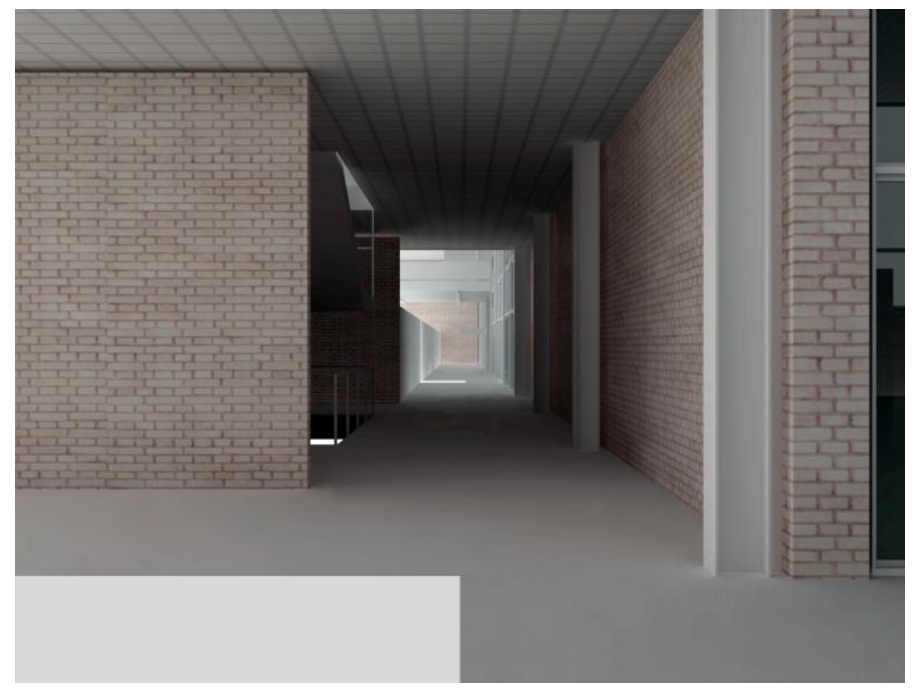

Imagen 9. Sala de lectura con la bodega de libros y la zona de oficinas en dos niveles (a), planta constructiva de la bodega de libros y el corredor (b), simulación del detalle del encuentro entre estructura y muro en la bodega de libros (c) y corredor que conecta la sala de lectura con el vestíbulo principal y el mezzanine $(\mathrm{d})$.

marco de la carpintería sea una HE cortada que se relaciona directamente con el ala de la columna, mientras que en el lado Este y Oeste, cuando la relación tiene que darse con el alma de la columna, la 
HE se suelde a una platina metálica que se sujeta a la columna a través de dos ángulos de lados iguales. La estructura y el cerramiento en los alzados Este y Oeste del patio interior están en el mismo plano. Para relacionar la columna y las carpinterías, en estos planos, se utiliza la misma solución de la esquina y el alma de la HE cortada es la transición visual entre elementos. Para vincular los planos Este y Oeste del patio interior con los muros ciegos de la bodega de libros se usa una solución similar a la esquina Sureste: una HE cortada soldada a la columna queda embebida en el muro ciego, es la transición entre el plano transparente de acero y vidrio y el plano de ladrillo visto opaco, cada uno en distinto eje.

(a)

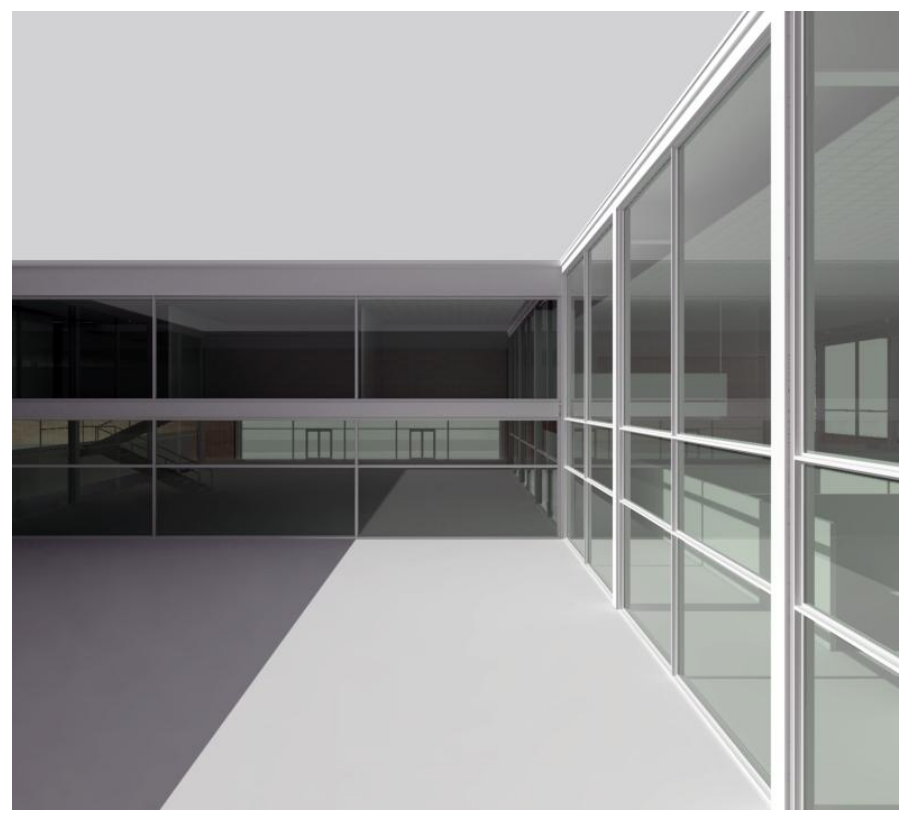

(b)

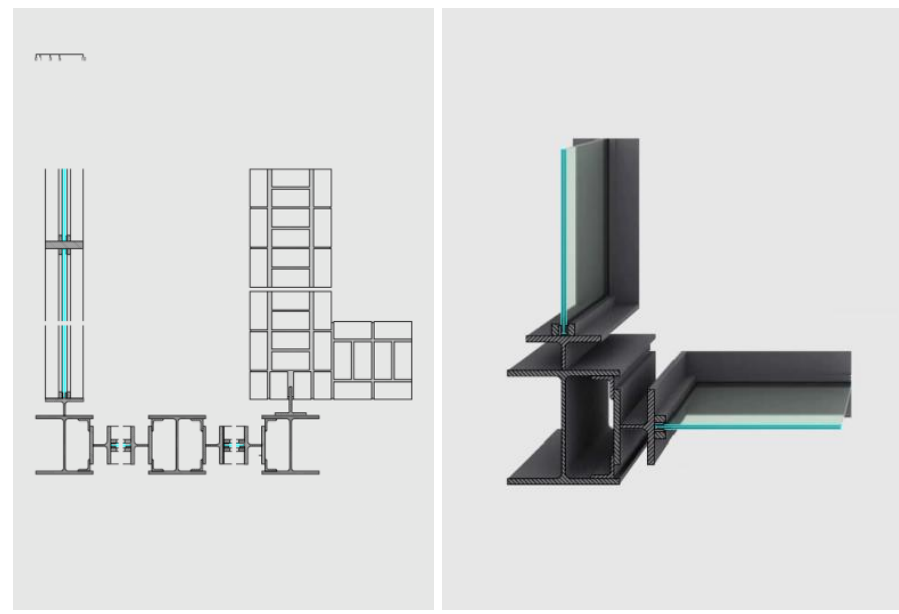

(c)

Imagen 10. Vista del patio interior con el mezzanine y el ingreso principal al fondo (a), planta constructiva del patio interior (b) y esquina sureste (c).

La relación entre el plano del patio y el de la bodega, desplazados entre sí y con materialidad y condición opuestas, se puede mirar en la Imagen 11(a). Este desplazamiento permite ver a cada espacio independiente el uno del otro, cada uno es una capa visualmente libre. La solución de la viga de borde de los alzados Este y Oeste del patio es la misma de la sección transversal de las fachadas Este y Oeste del edificio (Imagen 11(b) e Imagen 4(d)): lo interesante, en este caso, es que el cerramiento no es una "capa" independiente sobrepuesta sobre el eje de la estructura sino que cerramiento y estructura están en el mismo eje. 
(a)

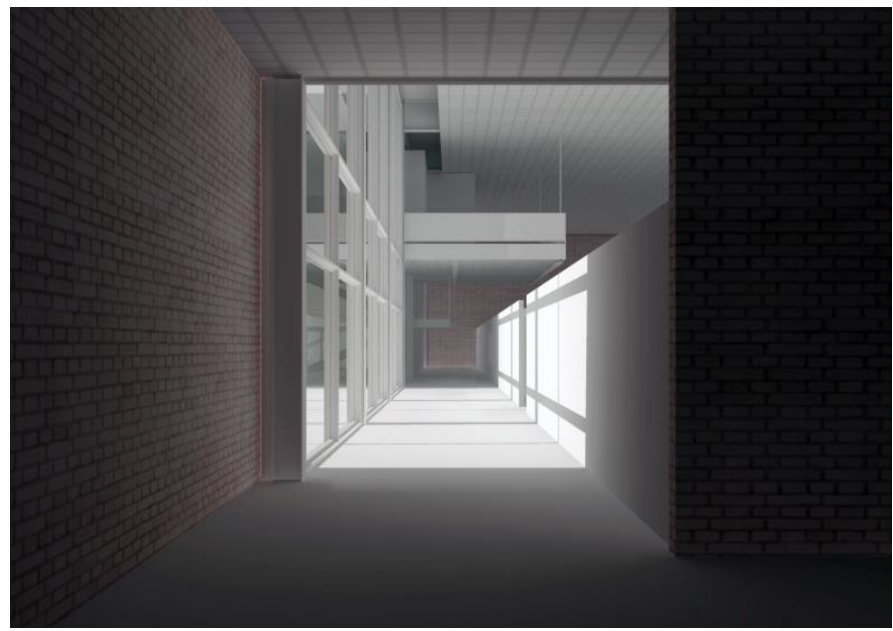

(b)

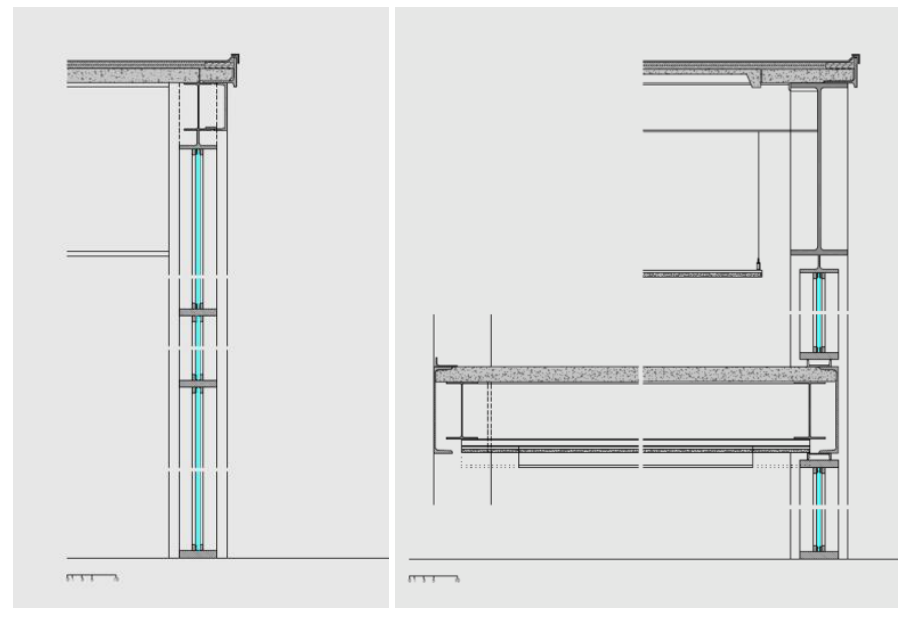

(c)

(d)

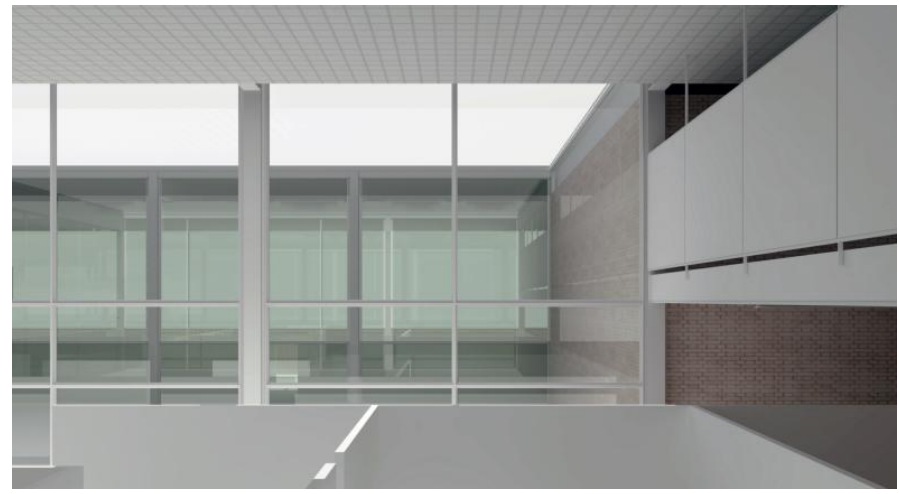

Imagen 11. Patio interior a la izquierda, oficinas con muro a media altura a la derecha y mezzanine al fondo (a), sección constructiva transversal en el alzado Este del patio interior (b), sección constructiva longitudinal a través del mezzanine (c) y zona de oficinas con tabiques a media altura (d).

Con Ludwig Mies van der Rohe no se deja nada al azar, se estudia la relación de las vigas transversales y longitudinales en la esquina Sureste del patio para que el resultado sea aceptable visualmente. Se verifica la continuidad estructural entre el exterior y el interior y la transparencia propia del vidrio. En la Imagen 11(d) se comprueba el efecto del patio interior: transparencias, iluminación, reflejos, relación entre planos opacos y transparentes, espacio continuo e infinito, relación entre distintas zonas, fluidez espacial tanto en el sentido horizontal como en el vertical. En la sección longitudinal (Imagen 11(c)) se ve que el forjado del mezzanine se cierra con una UPN y se utiliza una IPE como viga transversal. El cielo raso está a la misma altura que el ala inferior de la UPN de borde. Las vigas longitudinales, perfiles IPE, son de mayor altura que las transversales por lo que 
quedan vistas en la parte inferior: solución similar a la usada en la zona de servicios y oficinas (Imagen $8(\mathrm{~b} \mathrm{y} \mathrm{c})$ ). Hacia el patio la viga UPN de borde queda vista y se separa de las carpinterías con perfiles UPN de menor dimensión. El mezzanine, Imagen 12, es un plano que flota en el espacio de doble altura y confiere al espacio una monumentalidad no vista en otros edificios del IIT.

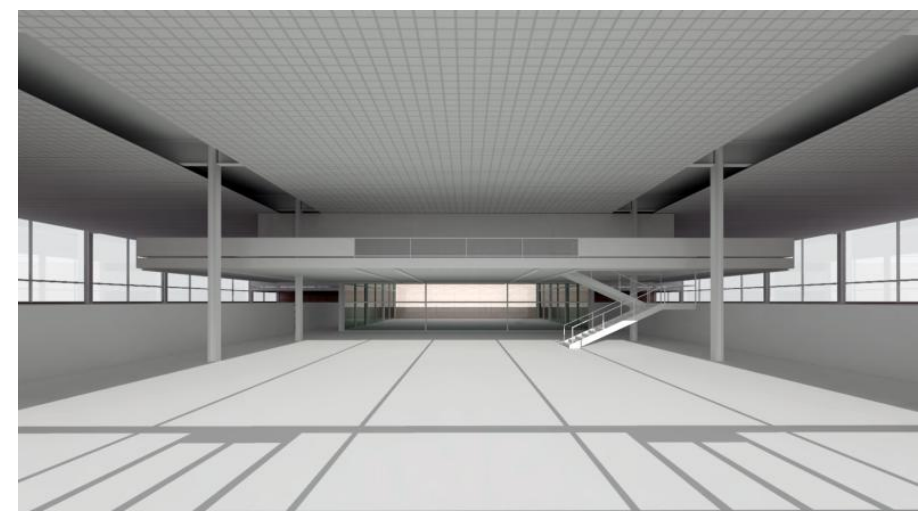

Imagen 12. Vestíbulo principal con el mezzanine y el patio interior al fondo.

\section{CONCLUSIONES}

La frase de Mies van der Rohe "Dios está en los detalles" manifiesta, sin duda, que la calidad de una obra se basa en la relación acertada y rigurosa de los materiales empleados. Se ha tratado de demostrar con este trabajo que el detalle es un instrumento de la concepción y no un corolario técnico, pues en el detalle se condensa, haciéndose más intensa, la formalidad esencial de su arquitectura. La solución intensa del detalle influye en la construcción de la forma y por ende en la calidad del proyecto. Se muestra además, que el sistema constructivo coincide con el sistema visual, es decir, que la construcción en sí, se convierte en un equivalente del ornamento constructivo del clasicismo. Una vez elige el sistema estructural, empieza a buscar las mejores relaciones entre materiales, y cuando se habla de mejores se hace referencia a las más económicas visual y constructivamente, a las más esenciales y abstractas, a las que posibilitan mayor rigor y precisión. Esta búsqueda demanda esfuerzo y dedicación y no siempre empieza de la manera más afortunada. Sin embargo, las soluciones finales, como se muestra, suelen ser las más consistentes.

La relación entre materiales, el encuentro entre elementos arquitectónicos y volúmenes con distinto comportamiento térmico, constructivo y funcional siempre tiene una transición visual. Se verifica, también, que la obra de Mies está construida por capas, así como el ojo, cuando es mirado con detenimiento, presenta un sinnúmero de colores y figuras, así también la obra de Mies van der Rohe tiene un sinnúmero de capas, unas más profundas que otras, cada una con textura y materialidad diferente. En nada se parece su obra a algunas obras contemporáneas en donde se pierde toda variación: algunas se parecen a un "ojo ciego" que poco o nada tiene que ver con la complejidad de la Arquitectura Moderna.

Con el trabajo se examinan las distintas posibilidades que una estructura clara y una definición del detalle riguroso y ordenado dan a la obra. Se detecta un proceso de variación y paulatina evolución hacia soluciones abstractas, esenciales, paradigmáticas y generales. Todo lo expuesto parte de un profundo proceso de mirada y pretende generar en aquel que lo lea la misma necesidad y satisfacción. El trabajo con maquetas, constante de su trabajo, demuestra el valor que Mies da a la mirada como elemento formativo y generador del proyecto. Sirve también recalcar que la construcción de la forma no tiene escala y por ende aquellos principios que sirven para construir forma en los detalles, son los mismos que se usan para construir ciudad. El edificio del Library and Administration Building, del Illinois Institute of Technology, contiene en sus paredes, el germen de las soluciones que Mies aplica en sus proyectos urbanos posteriores y, porque no decirlo, de los problemas del urbanismo actual. No se puede olvidar que el conocimiento acumulado del estudio del microcosmos deriva en la observación 
del macro universo. El entendimiento de lo mínimo nos permite ver a la ciudad como el momento de acción del arquitecto: el lugar donde plantear un futuro. El detalle intensifica la obra pero no la sustituye, básicamente lo que hace es darnos el punto de vista con el que mirar.

\section{BIBLIOGRAFÍA}

Carter, P., 1974. Mies van der Rohe at Work (1ª ed.). Pall Mall Press, Barcelona, España, 192 pp.

Lambert, P. (ed.), 2001. Mies in America ( $1^{\mathrm{a}}$ ed.). Canadian Centre for Architecture and Whitney Museum of American Art, Nueva York, EE.UU., 791 pp.

Martí, C., 2005. La Cimbra y el Arco. Fundación Caja de Arquitectos, Barcelona, España, 180 pp.

Neumeyer, F., 1995. Mies van der Rohe. La palabra sin artificio: reflexiones sobre arquitectura 1922/1968 (1ª ed.). El Croquis, Madrid, España, 492 pp.

Piñón, H., 2005. El Proyecto como (Re)construcción. Edicions de la UPC, S.L., Barcelona, España, $118 \mathrm{pp}$.

Piñón, H., 2009. Cinco axiomas del proyecto. En M.A. Hermida (coord.) Miradas a la Arquitectura Moderna en el Ecuador. Tomo 1: Cuenca: Maestría de Proyectos Arquitectónicos, Facultad de Arquitectura de la Universidad de Cuenca, Cuenca, Ecuador, 206 pp.

Punset, E., 2008. “Así aprendimos a contar”. Redes. Emisión 11-14 septiembre 2008. Temporada 13. (En línea). Descargado de http://www.redesparalaciencia.com/93/redes/redes-11-asiaprendimos-a-contar-29-min, el 15 de mayo 2009.

Schulze, F., 1985, Mies Van Der Rohe: A critical biography. The University of Chicago Press, Chicago, USA, $355 \mathrm{pp}$.

Schulze, F. (ed.), 1989. Mies van der Rohe: Critical essays. The Museum of Modern Art, Nueva York, EE.UU., 192 pp.

The Museum of Modern Art. The Mies van der Rohe Archive. 1986. Garland Publisher, New York, USA, Vol. 8, 9, 12 and 15. 